
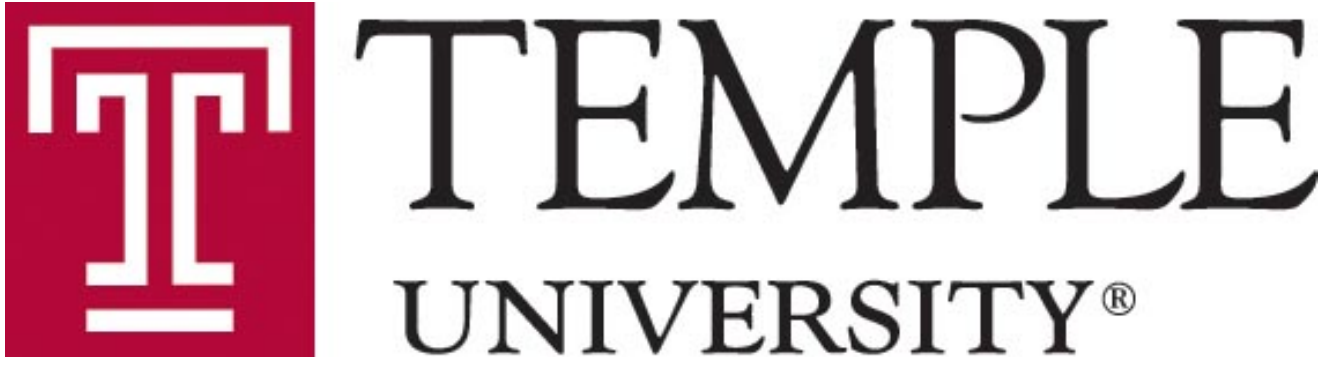

\title{
Road Rationing Policies and Housing Markets
}

\author{
Rhiannon Jerch \\ Department of Economics \\ Temple University \\ Panle Jia Barwick \\ Department of Economics \\ Cornell University \\ Shanjun Li \\ Dyson School of Applied Economics and Management \\ Cornell University \\ Jing Wu \\ Department of Construction Management \\ Tsinghua University
}

\author{
Department of Economics \\ DETU Working Paper 20-04 \\ January 2020
}

1301 Cecil B. Moore Avenue, Philadelphia, PA 19122

http://www.cla.temple.edu/economics/faculty/detu-working-paper-series/ 


\title{
Road Rationing Policies and Housing Markets
}

\author{
Rhiannon Jerch, Panle Jia Barwick, Shanjun Li, and Jing Wu*
}

December 12, 2019

For most recent draft, click here.

\begin{abstract}
Canonical urban models postulate transportation cost as a key element in determining urban spatial structure. This paper examines how road rationing policies impact the spatial distribution of households using rich micro data on housing transactions and resident demographics in Beijing. We find that Beijing's road rationing policy significantly increased the demand for housing near subway stations as well as CBD. The premium for proximity is stable in the periods prior to the driving restriction, but shifts significantly in the aftermath of the policy. The composition of households living close to subway stations and Beijing's CBD shifts toward wealthier households, consistent with theoretical predictions of the monocentric city model with income-stratified transit modes. Our findings suggest that city-wide road rationing policies can have the unintended consequence of limiting access to public transit for lower income individuals.
\end{abstract}

Keywords: road rationing, housing markets, urban structure

JEL Classification Codes: R21, R41

${ }^{*}$ Rhiannon Jerch is a postdoctoral researcher with Johns Hopkins University's 21st Century Cities Initiative and will join the Department of Economics at Temple University as an assistant professor in Spring of 2020, rhiannon.jerch@temple.edu; Panle Jia Barwick is an Associate Professor in the Department of Economics, Cornell University and NBER, panle.barwick@cornell.edu; Shanjun Li is a Professor in the Dyson School of Applied Economics and Management, Cornell University, NBER and RFF, SL2448@cornell.edu; Jing Wu is an Associate Professor in the Department of Construction Management at Tsinghua University. This project was supported by the Cornell University East Asia Program Area Studies Fellowship. We thank Gabriel Kreindler, Mike Lovenheim, Gilles Duranton, Nick Sanders, Nancy Brooks, Andrew Waxman, and Eric Zou for helpful comments, and Ziye Zhang and Lin Yang for excellent research assistance. 


\section{Introduction}

Several major cities around the world have implemented road rationing (or driving restriction) policies to address increasingly harmful levels of air pollution and traffic congestion. ${ }^{1}$ These policies generally restrict people's ability to drive within city limits on particular days of the week and during peak commute times. Permanent adoption of alternate-day-based road rationing policies has accelerated since the 2000's among some the world's largest urban centers (see Figure 1). Cities are a physical manifestation of people's desire to eliminate transportation costs. Thus, road rationing will likely affect not only pollution and congestion, but the ways in which people sort in space. This paper demonstrates how Beijing's road rationing is an important element in explaining declines in the rate of urban centralization among lower income groups since 2005.

Rapid urban growth in China since 1990 has increased automobile use within its large urban centers at a staggering rate. Between 2005 and 2015, the rate of car ownership outpaced population growth by three to one in Beijing. The Chinese government responded to degrading air quality and road congestion through several transit-oriented policies, including heavy investment in its subway network and a license plate-based road rationing policy in July of 2008 (hereinafter, CDR or "car driving restriction"). The CDR limited car owners from driving their car one day per week according to the last digit of their license plate. We exploit this shock to driving commute costs to test predictions of urban land use models developed by Alonso (Alonso 1964), Muth (Muth 1967), and Mills (Mills 1967) (hereinafter, “AMM”), and extended by LeRoy and Sonstelie (1983).

The monocentric concept of urban land use developed by AMM predicts that land prices, population, and employment densities diminish with distance from an exogenous urban core. If demand for housing increases with wealth at a faster rate than the time-cost of commuting, the AMM model predicts higher income groups will live further from the city center relative to lower income groups, a pattern consistent with several empirical studies of US cities (Lee and Lin 2017; Brueckner and Rosenthal 2009; Glaeser et al. 2008; Margo 1992; Gin and Sonstelie 1992). ${ }^{2}$ LeRoy and Sonstelie (1983) extended the AMM model to explain nineteenth century patterns of re-gentrification and urban decline. The main prediction of their model is that technological innovation in transit modes alters the comparative advantage of the rich relative to the poor for centralized locations: specifically, a new

\footnotetext{
${ }^{1}$ Air pollution is a primary concern for many urban areas. Over $80 \%$ of the world's major cities fail to meet World Health Organization guidelines on air quality (World Health Organization 2019). Emissions from vehicles is a particular concern in several developing nations, contributing to nearly $50 \%$ percent of particulate matter in Beijing (Viard and Fu 2015) and nearly 20\% in Delhi (Jain 2018).

${ }^{2}$ See Duranton and Puga (2015) for a literature review on patterns of residential sorting within cities.
} 
transit mode choice that is faster but expensive (e.g., a car) relative to existing transit (e.g., a bus or walking) will induce the rich to decentralize relative to the poor.

We develop a stylized model of urban land use following LeRoy and Sonstelie (1983) to illustrate the impacts of Beijing's road rationing policy on housing demand and the spatial distribution of income groups throughout the city. Our model has two main predictions: first, an increase to the cost of commuting by car will increase demand for housing proximate to areas of the city where people work and areas of the city where it is easier to substitute to alternative modes of travel. Second, the group most affected by driving costs (in our case, the rich) will outbid other groups for those areas.

Beijing provides a valuable context in which to test the monocentric city model and how changes to transit costs affect residential location choice for the following reasons. First, with over 21 million inhabitants, the assumptions of competitive bidding for housing underlying the monocentric city model is a reasonable assumption and theoretical predictions from the model are likely to be more appropriate than settings of a small city. Second, transit mode choice is largely stratified by income group in Beijing, unlike most US or European cities. Personal automobiles are expensive relative to average income levels in Beijing, and ownership is restricted to only those who can enter a lottery system and are lucky enough to win a license plate (Li, 2018). Lower income individuals generally rely on bus, subway, cycling or walking. This feature makes Beijing a particularly useful setting for testing predictions of LeRoy and Sonstelie (1983) because low income groups are very likely to utilize different transit modes from high income groups. Third, urban road rationing policies are enforced in more and more cities around the world, particularly in the developing world where air pollution from automobile exhaust is a particularly salient issue. The effects of these omni-present transit policies on housing markets and location choice is not well understood, but highly policy relevant.

This paper examines how a road rationing policy affects demand for both subway proximity and central business district proximity. We measure changes in demand for location amenities using changes in housing prices following Rosen (1974). We further explore how the policy affects the relative likelihood of income groups to sort near subway stations and Beijing's central business districts (CBD). The policy provides variation in the transit mode choice utilized disproportionately by high income households. We use this effective "natural" experiment to test how an increase in commuting costs among the wealthy affects housing demand and location choices across the income distribution.

Our analysis uses detailed, micro-level data on real estate transactions and buyer demographics of residents of Beijing. These data allow us to include a comprehensive set of controls on housing 
characteristics in addition to neighborhood-level fixed effects to account for unobserved differences in neighborhood desirability. Our empirical strategy effectively compares observationally similar housing units within the same neighborhood that vary in their relative distance to the nearest subway station and central business district. We exploit Beijing's road rationing as a city-wide unexpected increase in the cost of driving in a difference-in-differences approach to test how the premium for subway and central business district proximity changes as a consequence of the policy.

While our empirical approach employs fine-scale fixed effects to control for time-invariant differences across neighborhoods, our approach may be confounded by at least two factors occurring simultaneously over our period of study: first, Beijing's subway network expanded considerably. ${ }^{3} \mathrm{Li}$ et al. (2016) use variation in Beijing's subway expansion from 2001 to 2013 to show that property values increased by almost $1 \%$ for every 1 kilometer reduction in distance to a subway station. Second, Beijing's housing values experienced substantial appreciation during this time period. Prices grew an average of $13.6 \%$ per year, or roughly double that of the US housing market from 2000 to 2007 (U.S. Census 2019; Fang et al. 2016). ${ }^{4}$ If the housing boom and the subway expansion explain most of the change in housing prices before relative to after the CDR policy, our estimates on the road rationing effect will be spurious and will likely over-estimate the true effect.

We address these concerns in the following ways. First, we estimate hedonic and sorting effects dynamically, allowing the estimated effects to vary across time periods. This allows us to test for evidence of pre-CDR price or sorting trends. Our event studies show that the price premiums and sorting responses to subway and CBD proximity increase only after the CDR policy, suggesting that general price appreciation in the housing market does not explain our results. Second, we find the CDR premium effect persists even for neighborhoods that had pre-existing stations. Third, areas that received new subway stations did not exhibit differential income growth trends in the 2.5 years leading up to the station opening date. We interpret these findings as evidence that the post-CDR shift in the demand for subway proximity was unlikely to be driven by secular investment or gentrification trends in areas that received new subway stations.

Our analysis provides two key findings. First, we find that the CDR increased the premium for both subway station proximity and proximity to Beijing's CBD. Our preferred estimates show that road rationing increased the price differential for a housing unit one kilometer closer to a subway

${ }^{3}$ We plot the year-on-year expansion in Appendix Figure A1.

${ }^{4}$ We plot the mean annual price per square meter for housing among transactions within our sample in Appendix Figure A2. Holding a jiedao fixed, house prices grew an average of $13.6 \%$ per year. 
station relative to a house 1 kilometer further away by approximately $3.6 \%$ (or about $\$ 3,000$ for the average housing unit) compared to before the policy. Similarly, the price differential for a housing unit one kilometer closer to a central business district relative to a housing unit further away increased by $1.3 \%$ (or about $\$ 1,000$ for the average housing unit) compared to before the policy. Pre-trends show that the premium for proximity is stable in the periods prior to the road rationing, but shifts significantly in the aftermath of the policy. Our results imply that the Beijing bid-rent gradient for subway proximity was twice as responsive to the road rationing policy as prior literature suggests.

Second, we find modest but statistically significant evidence that the demographic composition of households near subway stations and the CBD shifted toward higher income households over the same period as the price adjustments. These findings are consistent with our model's predictions. Specifically, we find that the difference in distance to the CBD across two households differing in wealth by $10 \%$ increased by 0.5 percentage points (or about one-tenth of a kilometer) from a baseline difference in distance of $7.7 \%$ (or about 1.5 kilometers). In other words, if one household makes twice as much income as another, the wealthier household is likely to live approximately 1 kilometer closer to the CBD after the road rationing policy. We find a similar magnitude for the sorting response near subway stations. The difference in distance to subway stations across households differing in wealth by $10 \%$ increased by 0.8 percentage points (or about one-tenth of a kilometer) from a baseline difference in distance of $9.7 \% .^{5}$ Data patterns suggest these sorting results are driven by increased development and inflows of high income households as opposed to displacement of incumbent lower income households.

These findings are the first to demonstrate that driving restriction policies, aside from impacting the housing market, can impose additional impacts on the composition of income near transit accessible areas. Specifically, we find that lower income households are less likely to live in transit accessible areas relative to before the road rationing policy.

Our paper contributes to prior literature in the following two dimensions. First, this study contributes to the growing body of literature on urban road rationing. Most of these studies have focused on the effectiveness of road rationing policies at meeting their primary goals of reducing congestion and air pollution, with mixed results. ${ }^{6}$ In contrast to this literature, our paper explores

\footnotetext{
${ }^{5}$ We translate $0.5 \mathrm{pp}(0.8 \mathrm{pp})$ into one-tenth of a kilometer based on the mean pre-CDR distance to a central business district (subway) in our sample of $20.4 \mathrm{~km}(15.2 \mathrm{~km})$. We calculate the baseline difference in distance of $7.7 \%(9.7 \%)$ from a cross sectional regression of $\ln$ (Distance to CBD) ( $\ln$ (Distance to Subway)) as a function of $\ln$ (household income) with year-by-month fixed effects.

${ }^{6}$ Locations that manage to obtain high compliance with the policy (Carrillo et al. 2016; Viard and Fu 2015; Chen et al.
} 
how urban road rationing impacts the demand for housing and the subsequent re-sorting of high relative to low income groups. Our paper is most similar to Xu et al. (2015), which finds that prices for housing near subway stations increased in the six months following Beijing's road rationing. We extend their study to examine underlying household sorting and changes in the spatial distribution of residential wealth due to the policy.

Second, this paper relates to prior studies concerned with the positive relationships between inter-city location choices among the poor as a function of public infrastructure access (Glaeser et al. 2008; Brueckner and Rosenthal 2009; Brueckner et al. 1999; Baum-Snow and Kahn 2000). We consider sorting and price effects in areas proximate to subway stations because subway transit is a viable alternative to private vehicle use. While not the only focus of our paper, our hedonic analysis of subway proximity fits into a large body of literature that demonstrates train and subway access capitalize positively into housing prices. Redding and Turner (2015) provide a comprehensive review of this literature. Most of this literature relies on subway or transit network expansion to infer valuation of access (Tsivanidis 2019; Severen 2018; Gibbons and Machin 2005; Billings 2011; Li et al. 2016). In contrast, our hedonic estimates can inform the optimal provision of transit technology when private vehicle use is restricted - a scenario increasingly prevalent among the world's largest cities. In general, our results underscore the importance of transportation infrastructure and transit technology as a determinant of urban spatial structure. While investment in transit infrastructure has been shown to attract the poor (Glaeser et al. 2008) to public transit and the city center, we demonstrate that increasing commute costs for the wealthy can actually disperse the poor as they are outbid by the rich in these areas.

\section{Background and Data Description}

At least 75 million people around the world are affected by road rationing policies. Athens, Greece implemented the first of these alternate-day travel restrictions in 1982. Most policies restrict about $20 \%$ of personal vehicles from using central urban roadways on any given work day. In this section, we provide background information on Beijing's road rationing and discuss data sources and sampling restrictions.

2013; Gu et al. 2017) and restrictions that target high-emission vehicles (Wolff 2014; Barahona et al. 2018) appear to experience improvements to air quality following road rationing, whereas locations with low compliance or the possibility of substituting behaviors experience little change in air pollution (Gallego et al. 2013; Davis 2008; Zhang et al. 2017; Eskeland and Feyzioglu 1997). 


\subsection{Road Rationing in Beijing}

Beijing's road rationing policy went through several iterations between 2008 and 2011, generally leading to more lenient restrictions. Government officials first announced the policy in June of 2008 as a temporary restriction that would extend through the Olympic and Paralympic Games from late July to late September 2008. Initially, private vehicle owners could only drive their vehicles within the city every other day based on an odd-even schedule. The policy was enforced seven days a week nearly all day, except for three hours from midnight to 3am. At the end of this temporary restriction, the government decided to continue with the policy through April of 2009.

In its second phase, the policy relaxed its restriction on vehicle use to one day per week within (and including) the Fifth Ring Road during week days from 6am until 9pm. A driver's restricted day was based on the last digit of their vehicle's license plate number. A driver's relevant restricted day would rotate every four weeks. When this half-year trial ended, the government, again, announced an extension of the policy through April of 2020. This new policy restricted car use within, but excluding the Fifth Ring Road, rotated restricted days every 13 weeks, and reduced the restricted hours from 7am to $8 \mathrm{pm}$. This final iteration of the policy still stands today. Buses, taxis, and public-use vehicles for the police and military are not affected by the restriction (Viard and Fu 2015). The Chinese news media covered the restriction in early 2008, following a brief four-day trial period one year prior to the Olympics in Fall of 2007 (Hooker 2008). Thus, it is possible that people may have learned and responded to the policy months before its implementation. ${ }^{7}$

Viard and Fu (2015) found that Beijing's road rationing reduced particulate matter $\left(P M_{10}\right)$ by $21 \%$, with strong compliance and little evidence of inter-temporal substitution (i.e., driving more during non-restricted hours) or an increase in total number of vehicles in circulation, as in Davis (2008). In Beijing, it is difficult to evade detection because cameras throughout the city (as opposed to police) monitor the plates on vehicles. If an individual violates the restriction, they are fined roughly $\$ 30$ per violation. Further, Beijing restricts people's ability to purchase a second car, and purchase of a first car is regulated by a lottery system. The limited scope for noncompliance or substituting behavior were key to the success of Beijing's CDR in improving air quality. Given the strong compliance, how did this policy impact the distribution of wealth through Beijing?

Transit mode choice is stratified by income in Beijing. While we do not observe transit mode

${ }^{7}$ Google search trends related to "Beijing Odd Even" road rationing shown in Appendix Figure A3 suggests this is the case. 
choice among the home buyers in our data, aggregated statistics on mode choice by income group from the 2010 Beijing Household Travel Survey (Beijing Transport Institute 2010) supports our prediction that the CDR binds mainly for the wealthy who can afford cars. Figure 2 plots the distribution of mode choice by income group as of 2010 . Nearly $40 \%$ of earners in the top income bracket relied on cars to commute to work, while less than $20 \%$ of earners in the bottom income brackets relied on cars to commute. For public transit, just $14 \%$ of the top earners relied on public transit (subway or bus), whereas $20-21 \%$ of individuals in the bottom income bracket chose to commute by subway or bus. Although subway transit fares are heavily subsidized by the Beijing government at about $\$ 0.30$ per trip, ${ }^{8}$ walking and biking are the dominant modes of commute among most lower income groups (Beijing Transport Institute 2010). Research by Gu et al. (2017) further supports that the restriction was mainly binding for higher income groups. They use the 2010 travel survey to show that wealthier commuters were twice as likely to switch from auto use to an alternative mode on restricted days compared to lower income groups who rely on public transit, biking or walking.

\subsection{Data Sources \& Description}

Our empirical analysis requires information on housing prices, residential locations, and household income. We assembled this information using individual real estate transactions sourced from two major Beijing real estate firms; as well as mortgage loan applications sourced from an anonymous government-backed mortgage provider. ${ }^{9}$ The real estate data comprise approximately $17 \%$ of all housing purchases within Beijing from 2006 through 2012. Our sample of mortgage contracts comprises the majority of the mortgage market in Beijing during the sample period, though the precise market share is difficult to quantify because mortgage loans made to individuals not participating in the government-backed loan program (e.g., individuals at non-salaried jobs, individuals working part-time or unemployed, or the very wealthy) will not be represented in our data.

The Beijing government enacted several city-wide policies throughout our sample period that

\footnotetext{
${ }^{8}$ Fares became distance-based after 2014, however trips within the 4th Ring Road (under 22 kilometers) were still relatively cheap, averaging about 5 yuan per trip.

${ }^{9}$ The anonymous mortgage provider operates as a government-backed credit market to encourage home ownership especially for low- and middle-income households. In absence of a formal credit market, people can access loans through their employers (Tang and Coulson 2017). At participating employment firms, each employee and his/her employer have to contribute a specific percentage of his/her monthly income from the employer to the government-backed mortgage account. The employees can then obtain a mortgage loan with a subsidized interest rate for home purchase (about 1.5 percentage points, or nearly $30 \%$, lower than the commercial banks' mortgage rate. Virtually all eligible home buyers would apply for this mortgage first before going to other sources of funding. The data cover the universe of all home purchases in the city that made use of a government-backed mortgage loan from 2006 to 2013. Mortgage refinancing is uncommon in China, and there are no refinancing observations in the sample. As a result, each mortgage contract refers to a housing transaction.
} 
likely impacted the housing market and demand for automobiles. ${ }^{10}$ Our main specifications use the transactions occurring between July 2006 and July 2010 to mitigate potential spurious correlations from these other policies. Each housing transaction contains the sale or rental price as well as descriptive information on the housing unit (including number of bedrooms, floor level, decoration level, types of appliances, etc.) and information on the housing complex (including geographic location, total size, parking availability, green space, proximity to key schools, etc.). The mortgage loan data also provide information on housing unit price and descriptive information on the housing complex building. Importantly, the mortgage data provide detailed information on the loan applicant's demographic characteristics, including their income, education levels, and place of employment.

Figure 3 shows the spatial distribution of our sample of housing units throughout Beijing. Housing units are concentrated near the city center and near subway lines shown radiating outward from the Second Ring Road. Beijing is divided into 18 districts indicated by the thick green lines, each of which contains several smaller neighborhoods. The real estate transaction data identifies the "jiedao" of a housing unit, whereas the mortgage loan application data identifies the zip code of a housing unit. Jiedao are administrative units similar to a census tract, whereas zip codes are used for mailing addresses. They are similar in size: each district of Beijing contains an average of 35 jiedao, whereas districts contain an average of 32 zip codes. Throughout this paper, we refer to jiedao and zip codes collectively as "neighborhoods," however our estimation strategies define unique fixed effects for each level of geographic organization.

Figure 4 shows the location of Beijing's major employment centers. Beijing has at least six major employment centers located at various quadrants of the city. The city's geographic center is not a traditional business district, which is generally an assumption of the monocentric city model, but mainly a cultural and consumer-oriented district. For this reason, we define the Beijing "central business district" (CBD) as a relative measure and assign the closest major employment center as a given housing unit's CBD. In subsequent robustness checks, we find our results are generally insensitive to alternative definitions of Beijing's CBD.

Our identification strategy exploits variation in the housing price-distance gradient before and after the CDR policy within a neighborhood of Beijing. Figure 5 demonstrates our within-

\footnotetext{
${ }^{10}$ For example, in January 2012 the government implemented a lottery system for purchases of automobile license plates in order to limit the total vehicle fleet on Beijing's roadways (see Lu (2018) for an analysis of the license plate restriction on Beijing's housing market). In April of 2011, the government enacted an anti-speculative policy that restricted home purchases for natives, and prohibited home purchases for non-natives of Beijing (see Sun et al. (2017) for analysis of the home purchase restriction on Beijing's housing market).
} 
neighborhood variation. The jiedao are outlined by the thick black lines. Among our data sample, each jiedao experienced an average of 802 transactions while each zip code experienced an average of 194 mortgage loan applications. We restrict our analysis to housing units within the Sixth Ring Road of Beijing which skews the sample of neighborhoods toward those with smaller square areas. ${ }^{11}$ Our sample covers roughly two-thirds of the 300 jiedao within Beijing and over $90 \%$ of the 200 zip codes. The median area of a jiedao in our sample is approximately 1.65 square miles. By identifying the gradient change estimates off of time-wise variation within a small geographic unit, we are able to control for unobserved differences in amenities across Beijing neighborhoods, such as the existence of high quality shops or restaurants.

Table 1 provides summary statistics on a subset of the variables available within each of our datasets. The purchase price varies considerably more in the real estate data as compared to the mortgage dataset. The mortgage data housing units are also further from the city center and further from subway stations, on average. This is partially due to the selection of individuals represented by the mortgage data, which overrepresent the middle class demographic. Home buyers able to utilize the government-backed mortgage loan system are less likely to be entrepreneurs or independently wealthy.

The year-on-year frequency of transactions in our real estate sample correlates closely with Beijing's housing market (shown in Appendix Figure A4). Beijing's housing market contracted during the 2008 global recession. At the end of that year, the Chinese government implemented a series of aggressive housing market policies, including lowering mortgage interest rates and down payment requirements, which led to a massive rebound in 2009. In April of 2010, Beijing's local government implemented housing market cooling measures to avoid a speculation-driven housing bubble, including increasing the minimum down payment required for purchasing a second home and subsidizing construction of affordable housing. These anti-inflationary policies remained in place through 2014, which is why the transaction volume never reached 2009 levels.

\section{Theoretical Framework}

We predict how a city-wide road rationing policy will affect the sorting of low relative to high income individuals through the stylized AMM monocentric city model, and its extension by LeRoy and Sonstelie (1983). We then discuss application of our model to Beijing's road rationing policy and explore relevant data patterns across house prices, proximity, and household income.

\footnotetext{
${ }^{11}$ Appendix Figure A5 shows the cumulative distribution of jiedao size within our sample compared to that of the Beijing population.
} 


\subsection{Residential Equilibrium \& the Bid-Rent Function}

Consider a monocentric city with a central business district (CBD) where all residents supply work at wage $w$ to earn $y$ income. Residents live outside the CBD in the residential district of the city. Commute time increases monotonically with distance from the CBD. There are two possible modes of traveling to work: car or subway. Consumers decide where to live, choosing a pair of location parameters $(x, \delta)$ where $x$ is the distance from the CBD to an individual's residence and $\delta$ is the distance from location $x$ to the nearest subway station. Consumers choose the pair $(x, \delta)$ so as to maximize consumption of housing $h$ with price $p$ and the numeraire good $z$ with price one. Individuals commute distance $x$ if they commute via car and distance $(x+\delta)$ if they commute via subway; and pay $w t(n, x, \delta)$, the time cost of commuting. $t(n, x, \delta)$ describes transit time, and is a function of distance to $\operatorname{CBD} x$, distance to the nearest station $\delta$, and the likelihood of commuting via subway $n$. Discussed in greater detail below, $n$ can vary with commuter type (rich versus poor) and the existence of road rationing days. Our empirical approach focuses on price and sorting effects over a relatively short time horizon of two to four years, consequently we assume that the city boundary is fixed, housing supply is fixed, and the city is closed, without in or out migration. Residents face the following maximization problem:

$$
\begin{gathered}
\max _{z, h} U(z, h) \text { s.t. } \\
z+p h+t(n, x, \delta) w=y
\end{gathered}
$$

Assume that there are two modes of transit, car or subway. Transit time $t(n, x, \delta)$ from any distance $x$ to the CBD depends upon the transit mode and the speed of the transit mode. Driving transit time is $x / \nu$. Subway transit time includes two components. First, walking time to the subway station $\delta$ divided by walking speed $\omega$; and second, transit on the subway to the $\mathrm{CBD}, x / \sigma$. That is, transit time via subway is $\frac{\delta}{\omega}+\frac{x}{\sigma}$. For any $x$, we assume driving is a faster mode of transit than taking the subway: $\frac{x}{\nu}<\left(\frac{\delta}{\omega}+\frac{x}{\sigma}\right)$. Transit costs are defined as follows:

$$
t(n, x, \delta)=n\left[\frac{\delta}{\omega}+\frac{x}{\sigma}\right]+(1-n) \frac{x}{\nu}
$$

In equilibrium, residents choose a housing location $(x, \delta)$ such that:

$$
\begin{array}{ll}
\frac{\partial p}{\partial x}=-\left[\frac{n}{\sigma}+\frac{1-n}{\nu}\right] \frac{w}{h} & \text { and } \\
\frac{\partial p}{\partial \delta}=-\left[\frac{n}{\omega}\right] \frac{w}{h} &
\end{array}
$$

Thus, the price of housing falls with distance enough to compensate individuals for their longer commutes. Ex ante, both choice of $x$ and $\delta$ matter for individuals commuting via subway, but only the 
choice of $x$ matters for individuals commuting via car. Eq. 2 describes the bid rent for distance from the CBD, holding $\delta$ constant, whereas Eq. 3 describes the bid-rent for distance from a subway station holding $x$ constant. In Appendix B, we show the derivation of Eq. 2 in greater detail.

\subsection{Heterogeneity by Mode Choice}

Groups facing different preferences for housing consumption $h$ and time costs $w t(n, x, \delta)$ will have their own distinct bid-rent gradient. LeRoy and Sonstelie (1983) develop the case where a highincome group, possessing greater opportunity cost of time, commute via car. Cars are more expensive but a faster transit mode relative to public transit. The poor rely on public transit since it is not economical for them to commute via car. This setting is quite applicable to Beijing where wealthier people use cars and the lower income rely on public transit. Following LeRoy and Sonstelie (1983), assume there are two consumer types $i$ : rich and poor. Each consumer type will differ in their wage, housing consumption, and likelihood of commuting via subway. We introduce an index $i$ for each of these variables $\left(w_{i}, h_{i}, n_{i}\right)$ where $i=p, r$. Subscript $p$ denotes the housing consumption, wage, and transit mode of the poor and $r$ the same for the rich. For the poor, $n_{p}$ approximates 1 because the poor are very likely to rely on subway transit. The rich rely on cars, but the rich may use either mode depending on effective road rationing days, thus: $0 \leq n_{r}<n_{p} \sim 1$.

Rearranging Eq. 2, the poorer group will have a steeper bid-rent gradient than the rich and, therefore, live closer to the city center if and only if:

$$
\begin{aligned}
\frac{h_{r}}{h_{p}}>\frac{\partial t\left(n_{r}, x, \delta\right) / \partial x}{\partial t\left(n_{p}, x, \delta\right) / \partial x} \times \frac{w_{r}}{w_{p}} & =\frac{n_{r} / \sigma+\left(1-n_{r}\right) / \nu}{n_{p} / \sigma+\left(1-n_{p}\right) / \nu} \times \frac{w_{r}}{w_{p}} \\
& \approx \frac{n_{r} / \sigma+\left(1-n_{r}\right) / \nu}{1 / \sigma} \times \frac{w_{r}}{w_{p}}
\end{aligned}
$$

Beijing's road rationing, operationalized by an increase in $n_{r}$, serves to change the ratio of transit time costs for the rich car users relative to the poorer subway users. As the road rationing pushes a rich resident to utilize the subway, the ratio $\frac{n_{r} / \sigma+\left(1-n_{r}\right) / \nu}{1 / \sigma}$ moves closer to parity, and thus Eq. 4 is less likely to hold following Beijing's road rationing. This logic tells us that higher-income individuals will find housing close to the city center more attractive, and will consequently move closer to the city center following the road rationing.

Similarly, poor households will live closer to subway stations, conditional on $x$, if Eq. 3 is steeper for the poor relative to that of the rich:

$$
\frac{h_{r}}{h_{p}}>\frac{w_{r}}{w_{p}} \frac{n_{r}}{n_{p}}
$$

As $n_{r}$ increases, the road rationing makes Eq. 5 less likely to hold. Collectively, this logic tells us that 
higher-income individuals will move closer to the CBD and closer to subway stations, conditional on location $x$, following the city-wide road rationing.

\subsection{Application to Beijing's Road Rationing Policy}

An advantage of our setting is that we isolate shifts to the bid-rent gradients, as opposed to their actual slopes. Several factors can confound empirical estimates of $\frac{\partial p}{\partial x}$ in Eq. 2 or $\frac{\partial p}{\partial \delta}$ in Eq. 3, such as proximity to high quality schools or proximity to recreational amenities (i.e., parks or restaurants). Omission of such unobserved factors will bias the price-distance gradients, either downward in the case of positive correlation of proximity and desirable amenities; or upward in the case of a proximity and disamenities, such as the prevalence of noise and congestion near the city center or subway stations. ${ }^{12}$ While use of spatial fixed effects can correct for some of the omitted variable bias, there is a problematic tradeoff between employing fixed effects at a fine-enough scale to remove all spatiallydependent amenity variation, and identification of the bid-rent gradient.

Beijing's road rationing policy served to shift both gradients. Consequently, we can identify plausibly exogenous changes to the bid rent and changes in demographic composition through estimating the second derivative of both equations with respect to $n$ as follows:

$$
\frac{\partial^{2} p}{\partial x \partial n}=-\frac{w}{h}\left[\frac{1}{\sigma}-\frac{1}{\nu}\right]
$$

and

$$
\frac{\partial^{2} p}{\partial \delta \partial n}=-\frac{w}{h} \frac{1}{\omega}
$$

Eq. 6 provides the rate of change in the price versus distance-to-city-center trade off, all else equal, as the likelihood of subway use increases following road rationing. Similarly, Eq. 7 provides the rate of change in price versus distance-to-subway station trade off, all else equal, as the likelihood of subway-use increases following road rationing. Our empirical approach will estimate changes in both bid-rent gradients, and then test predictions of the model on sorting of lower relative to higher income households near the CBD following Eq. 4 and subway stations following Eq. 5.

Figure 6 plots the bid rent gradients before and after the road rationing policy. Eqs. 6 and 7 are effectively the difference in slopes show in these figures for CBD and subway gradients, respectively. The price premium per square meter for subway access clearly increases following the road rationing policy in Panel B. The premium for access to the CBD in Panel A is less striking, but still demonstrates

\footnotetext{
${ }^{12}$ Beijing's subway network is entirely underground, thus the infrastructure itself does not alter the visual appeal of a particular location. However, there may be some dis-amenity from living directly beside a subway station due to heavier foot traffic or noise.
} 
a slight tilt from the pre-CDR period. These price dynamics are intuitive if both the rich and poor are competing for housing proximate to subway stations, but less so for proximity to the CBD. The poor are not impacted by the road rationing, thus do not compete for housing close to the city center. Both rich and poor, however, prefer housing closer to subway stations, all else equal.

Figure 7 shows the relationship between income and distance to the CBD in Panel A and the nearest subway station in Panel B, respectively. The decentralization of the lower-income relative to the higher-income is prevalent in the raw data. Both gradients have become steeper over time, particularly for subway proximity. In the most recent period, Beijing appears similar to older US and European cities in its demographic spatial structure as average income declines with distance from the CBD (Brueckner et al. 1999). However, these patterns are a marked shift from the pre-road rationing period, when the relationship between income and CBD proximity was weaker. Income and subway proximity appear almost uncorrelated in the pre-period in Panel B. The slight positive relationship is consistent with the theoretic predictions of Glaeser et al. (2008), whereby lower income individuals tend to sort near transit oriented locations. ${ }^{13}$

\section{Empirical Approach}

We first explore how Beijing's transit policies impact demand for housing near the city's CBD and near subway stations. The residential locations of the rich relative to the poor will be driven by changes in their willingness to pay for proximity.

Let $i$ index housing units, $j$ index jiedao, ${ }^{14} t$ index the day of a transaction, and $q$ index one of 28 quarters. We estimate the effect of the CDR policy on the distance-to-subway (and distance-to-CBD) price premium through the following event study specification:

$$
\ln \left(p_{i j t}\right)=\sum_{q=1(\ni 15)}^{28} \delta_{q}\left(K m_{i t} \times D_{q}\right)+\alpha K m_{i t}+\mathbf{X}_{\mathbf{i j t}} \theta+\gamma_{j}+\tau+\varepsilon_{i j t}
$$

where $p$ is the price of housing per square meter, $K m$ measures the distance to the nearest subway station or business district, and $D_{q}$ is a series of indicator variables equal to one for each quarter from 2005 through 2011. $\mathbf{X}$ is a vector of controls for housing unit and building complex attributes and $\gamma_{j}$ and $\tau$ are jiedao and time fixed effects, respectively. $\tau$ includes year and month fixed effects in our main specification, but we apply finer-scale time fixed effects in various specifications. The parameters $\delta_{q}$ measures the difference in the housing price-distance gradient in quarter $q$ relative to the baseline

\footnotetext{
${ }^{13}$ Appendix Figure A6 and A7 plot the income-distance gradient and price-distance gradients, respectively, for alternative definitions of Beijing's CBD. In nearly all cases, the post-period gradient becomes steeper.

${ }^{14}$ Jiedao is a neighborhood that usually contains several apartment complex on a street or street segment. In our sample, a Jiedao has an area of approximately 1.65 square miles
} 
third quarter of 2008, which is quarter 15 in our sample. ${ }^{15}$ We cluster standard errors $\varepsilon_{i j t}$ at the jiedao level. We estimate the coefficients of interest, $\delta_{q}$ using variation in CBD and subway proximity over time within a jiedao. These fixed effects remove confounding unobserved differences in amenities across Beijing neighborhoods, such as the existence of high quality shops in the central Xidan district or proximity to premiere universities in the northwest Haidian district.

Inequalities in Eqs. 4 and 5 provide conditions for lower income groups to live closer to the city center and near subway stations, respectively. Both conditions are less likely to hold following the CDR if the likelihood of commuting via subway among the rich $\left(n_{r}\right)$ increases more than that of the poor $\left(n_{p}\right)$. We predict this result will obtain because, as shown in Figure 2, wealthier income groups utilize private vehicles to commute more than lower income groups.

In our model, house prices adjust as a result of higher income groups outbidding lower income groups for proximate locations. As higher income groups move, the average income in areas proximate to subway stations and business districts will change. To test predictions of our model, we employ data on household income, demographics, and location from the mortgage application data. We estimate the relationship between household income and proximity over 28 quarters spanning the CDR policy from 2005 through 2011 in a flexible event study specification:

$$
\ln \left(K m_{i z t}\right)=\sum_{q=1(\ni 15)}^{28} \alpha_{q}\left(\ln I_{i z t} \times D_{q}\right)+\delta \ln I_{i z t}+\mathbf{Z}_{i z t} \theta+\zeta_{z}+\tau+\mu_{i z t}
$$

where $i$ indexes housing units (equivalently households), $z$ indexes zip codes, $t$ indexes the day of a mortgage application, and $q$ indexes on of 28 quarters. $K m$ is the distance from housing unit $i$ to the nearest subway station or business district, $I$ is the monthly household income for the primary and secondary earners purchasing housing unit $i$ at time $t$, and $D$ is, as before, a series of indicator variables equal to one for each quarter from 2005 through 2011. The vector $\mathbf{Z}$ includes controls for housing unit attributes and characteristics of the primary and secondary earners of the household including age, education level, work tenure, employer industry type, and position rank. These demographic controls remove potential sorting responses due to unobserved changes to labor demand or changes to the location of employers. $\mathbf{Z}$ also includes controls for distance to the nearest subway station in the CBD sorting regressions; and distance to the nearest CBD in the subway station regression. The fixed effects $\zeta_{z}$ and $\tau$ control for time-invariant characteristics of housing location $i$ and macro-economic trends effecting all housing units, respectively. In our main specification $\tau$ includes year and month fixed effects. $\alpha_{q}$ provides the elasticity of distance with respect to income in quarter $q$ relative to the

\footnotetext{
${ }^{15}$ We choose a log-linear specification for ease of interpretation, however we show in Appendix Table A2 that our results are robust to a log-log specification used in Xu et al. (2015).
} 
third quarter of 2008, quarter 15 in our sample. We cluster standard errors $\mu_{i z t}$ at the zip code level.

\subsection{Identification Challenges}

Our empirical approach is subject to two main threats to identification of $\delta_{q}$ in Eq. 8 and $\alpha_{q}$ in Eq. 9. The first one is unobservables that could have changed at the time of the policy and also affect the outcome variables (prices or location choices). That is, price changes could have occurred absent the road rationing policy if areas near CBD and subway stations were on a differential growth trajectory relative to the areas far from CBD and subway stations. For instance, if dining, shopping, and entertainment establishments grew over time in the same areas as subway stations and CBDs, then bid-rent gradients could have become steeper over time due to growth in these amenities, as opposed to the road rationing policy. If these correlated time-varying trends capitalized positively into housing prices, an ordinary least squares (OLS) estimate of $\delta_{q}$ in Eq. 8 would over-estimate the effect of the road rationing. If, however, correlated time-varying trends are "bads", like noise and congestion rather than the aforementioned "goods", an OLS estimate of $\delta_{q}$ would under-estimate the effect of the road rationing.

Similarly, OLS would not provide a consistent estimate for $\alpha_{q}$ in Eq. 9 if mean proximity to CBDs or subway stations would have increased for higher income households absent the road rationing policy. In other words, if amenities like high quality shopping and dining grew over time near subway stations or CBDs, and these types of amenities disproportionately attract higher income individuals, then the composition of income near these areas would have increased regardless of the road rationing policy.

The identifying assumption is that housing prices and location choices would have trended similarly with respect to their distances to subways and CBDs in absence of the road rationing policy. We can test the plausibility of this assumption by examining trends in the price-distance or incomedistance gradients in quarters leading up to the road rationing policy. If the difference in price or income between proximate and far housing units is stable in periods leading up to the CDR, it is likely that the such differences would have remained stable in absence of the CDR. To test these assumptions, we present dynamic effects specifications that allow for the treatment effects of proximity on prices, and income on distance to flexibly vary over time. With this approach, we are agnostic as to the start date of the CDR. This allow us to visually examine if amenities (or dis-amenities) have grown near CBD or subway stations over time, and if these are capitalized into housing prices prior to start of the CDR in July of 2008. We further address this identification threat by including controls for 
district - specific linear time trends, as well as specifications with year-by-month fixed effects. Since some districts contain more stations and are closer to CBDs than others, these controls will remove unobserved growth (or decline) in proximity-correlated amenities that may impact prices or sorting.

The second main threat to identification is reverse causality. That is, proximity to CBDs or subways could have changed as a consequence of housing price or income growth over our time period. In this paper, we assign central business district centroids as static points that are unchanging over time by construction. Consequently, it is not possible in our setting for the location of CBDs to dynamically respond to gentrification patterns. Beijing's subway network, however, was growing over this time period, with additional lines and additional subway stops. If subway stations were sited in areas where house prices were expected to increase, or areas where the average income of residents was expected to increase, we would not be able to interpret our results as consequences of the road rationing policy. Li et al. (2016) argue that transportation planning in Beijing is largely disjoint from development and land-use planning. Nonetheless, we empirically test for possible siting endogeneity in several ways, including testing whether subway stations opened in gentrifying neighborhoods, reestimating our hedonic analyses excluding areas of the city where new subway stations opened, and testing for price growth trends in areas that received subway stations outside of our study period. Each of these robustness checks are described in greater detail in section 5.4. In general, we do not find evidence that new subway stations were more likely to open in gentryfing neighborhoods of Beijing.

\section{Empirical Results}

We now present evidence on the connection between housing demand and transit policies in Beijing. The road rationing policy increased transit costs for drivers. Our model, following LeRoy and Sonstelie (1983) predicts that changes in $n_{r}$ - the likelihood of commuting via subway for the rich - should shift the price-distance gradient as well as the residential location choices of those formerly relying on personal car travel relative to those relying on public transit.

\subsection{Road Rationing and Property Values}

First, we test the assumption that housing prices for proximate relative to distant housing units would exhibit common trends absent the road rationing policy. Figure 8 shows estimation results of Eq. 8, the event study of the CBD housing price premium. Prior to the road rationing, the price premium for CBD proximity is not significantly different from the road rationing quarter. There is a small increase of about $1 \%$ in the premium for proximity to the CBD following the road rationing, although each 
individual time-specific point estimates are often statistically insignificantly, likely an issue of sample size.

Regression results in Table 2 show that CBD proximity commands between 1.4 and 1.9\% (or between $\$ 1,100$ and $\$ 1,600)$ higher price per kilometer after the road rationing. The use of jiedao fixed effects in column (2) significantly increases the magnitude of the policy effect, implying unobserved dis-amenities can attenuate estimates of the CBD-proximity gradient. The jiedao fixed effects also serve to absorb nearly all cross-section variation between kilometers to CBD and price. Column (4) uses year-by-month fixed effects, such that variation is driven by transactions within the month of July 2008. In column (5), we apply controls for district-specific linear time trends to account for district-level growth that may be spatially correlated with subway proximity. The point estimate is stable across these various specifications. Estimates of the price gradient change under alternative CBD definitions in Appendix Table A1 are closer to 1\%, but within the range of $1.5 \%$ In column (6), we add over 2,000 fixed effects for housing unit building complex. Housing units within the same building complex have the same distance to the nearest business district, consequently the identifying variation in column (6) comes only from changes over time in the premium for proximity holding the distance $x$ fixed. The building complex fixed effects diminish the point estimate considerably. Thus, while housing units at different distances from the CBD within a jiedao exhibit differential price growth trends after the CDR, the same is not true for housing units at the same distance from a CBD.

We next consider the effect of the road rationing policy on demand for living close to a subway station. Figure 9 shows estimates of $\delta_{q}$ from Eq. 8 where $K m$ is distance to the nearest subway station. The price per square meter across housing unit that differ in their distance to the subway network did not vary significantly in the time periods leading up to the road rationing policy. However, starting in the first quarter following the CDR in July of 2008, the discount (premium) for subway distance (proximity) decreased (increased) by approximately 4\% per kilometer. Around April of 2011, there is an additional decrease (uptick) on the price discount (premium), which corresponds to a substantial restriction in the government's circulation of license plates and a lower likelihood of winning the license plate lottery (Li 2018).

Our regression estimates reaffirm that the price-subway proximity gradient became steeper following the road rationing policy. Results are robust to alternative controls, and finer time-location fixed effects. In Table 3, subway distance (proximity) ("Km to Subway") commands a 1\% to 5\% price discount (premium) per kilometer prior to the CDR policy. This level estimate may be biased 
if stations are sited endogenously, however we interpret the positive sign as consistent with subway distance (access) being undesirable (valuable) to city residents, all else equal. The interacted term shows that after the road rationing policy, housing units one kilometer further from a subway station sell for approximately $4 \%$ (or about $\$ 3,000$ ) less than a comparable housing unit one kilometer closer to a subway station. The effect attenuates slightly to $2.6 \%$ after using building complex fixed effects in column (6). Even with these fixed effects, demand for subway proximity increases over $\$ 2,000$ per kilometer, or double that of pre-CDR levels.

The city-wide road rationing policy increases the premium for subway access only within walking distance of subway stations. Figure 10 displays the non-parametric relationship between subway proximity and price following the CDR by plotting the mean price change for each half-kilometer bin relative to housing units outside of five kilometers from subway stations. The premium falls to zero after approximately three kilometers, or about 1.8 miles. Intuitively, subway proximity has no impact on housing prices outside of a reasonable walking distance from the station. Figures 10 supports our interpretation that demand for the subway network - as opposed to correlated, unobserved amenities - is the mechanism driving the price premium for proximity following the 2008 road rationing policy.

We assess the magnitude of our results using a back-of-envelope value of time calculation. The magnitudes of our price premium results are between 22 and $68 \%$ of the hourly wage, based on the CBD proximity premium and the subway proximity premium, respectively. ${ }^{16}$ These magnitudes seem plausible, considering prior literature generally finds a value of time-to-wage ratio of about 50\% (Small 2012).

Our results show that subway station access came to be in much higher demand relative to CBD access following the road rationing policy. Expansion of the subway network makes transitoriented housing locations more desirable for all marginal subway riders. However, the road rationing policy makes housing closer to the CBD more desirable only for marginal drivers with a high value of

\footnotetext{
${ }^{16}$ We calculate hours saved by moving one kilometer closer to either the CBD or a subway station as follows: walking speed of $15 \mathrm{~min} / \mathrm{km} \times 2$ walks per day $\times 1$ driving restricted day per week $\times 50$ working weeks per year $\times 2$ commuters per household $\times$ a 20 -year housing tenure $\div 60 \mathrm{~min} /$ hour $=1,000$ total hours saved per household by moving $1 \mathrm{~km}$ closer. Hedonic results in Tables 2 and 3 suggest the mean increase in purchase price for a housing unit $1 \mathrm{~km}$ closer to the CBD and subway was about $\$ 1,000$ (6,800 yuan) and $\$ 3,000$ (20,400 yuan) per kilometer, respectively. Dividing these premiums by the 1,000 hours saved gives an implied value of time of $\$ 3$ (20.4 yuan) and $\$ 1$ (6.8 yuan) per hour. As of 2007, the average resident in our sample living within $5 \mathrm{~km}$ of either the CBD or a subway station with non-zero income earned approximately 6,000 yuan per month, or about 30 yuan per hour (assuming they work 200 hours per month). Consequently, our hedonic CBD and subway estimates are about $22 \%$ and $68 \%$, respectively, of the hourly wage in our sample.
} 
time. Those wealthy enough to drive their cars are a relatively smaller portion of Beijing's population compared to those reliant on public transit, thus it is not surprising that the subway price effect is much stronger than the CBD price effect. Both results, however, are consistent with the LeRoy and Sonstelie (1983) prediction that changes to transit costs will alter the price-distance gradient.

\subsection{Comparing the Subway-Distance Premium with Prior Work}

Our results on the subway-price gradient are significantly larger than those of Xu et al. (2015), who find that the elasticity of price with respect to subway distance is $-0.02 \%$. We compare results directly in Appendix Table A2, where we employ the same 6-month time period, log-log specification, and start date for the CDR (October 11, 2008) as in Xu et al. (2015). Following Xu et al. (2015), we also exclude housing units located near newly-built subway stations, leaving approximately 19,000 observations. Columns (5) through (8) employ this paper's CDR start date of July 20, 2008 for comparison purposes. ${ }^{17}$ In column (1), we attempt to replicate their main result by including controls for location attributes, such as distance to the city center and dummies for whether the housing complex is located within a "key" school district. ${ }^{18}$ Our point estimate is within the range of their main result, but is three times larger in magnitude. We attribute the difference in our estimates to having substantially more spatial variation and a more representative data set of the broader Beijing housing market. The addition of detailed controls on the housing attributes reduce the estimates, but the effect is still more than double that of Xu et al. (2015).

$\mathrm{Xu}$ et al. (2015) additionally found that the subway distance premium after the road rationing policy ranged between $36-60 \%$ of the pre-restriction premium. We estimate the pre-restriction premium for subway accessibility in column (4) and (8) of Appendix Table A2 following Xu et al. (2015) where we limit the sample period to 6 months prior to the policy. Several confounding factors are likely correlated with subway proximity and housing desirability, thus we interpret columns (4) and (8) with caution. For comparison purposes, our results suggest that the post-restriction premium is double the pre-restriction premium, substantially greater than Xu et al. (2015). This underscores that not only was the gradient shift much larger than prior estimates suggest; but the magnitude of this gradient shift is of first order economic significance. This substantial difference in our results implies that subway proximity may be highly correlated with certain disamenities, like noise or congestion,

\footnotetext{
${ }^{17}$ We believe July 20 is the correct effective start date of the CDR because this was when the policy was implemented for the Olympic games. The policy restricted half of the vehicles from driving on a given work day based on the even or odd license numbers. The policy was modified and made more permanent in October of that year.

${ }^{18}$ Specifically, we replicate column 8 of Table 2 in Xu et al. (2015).
} 
that put downward bias on the housing price-subway distance gradient. Failure to control for these unobserved attributes can significantly underestimate the benefits of transit infrastructure.

\subsection{Road Rationing and the Demographic Sorting}

The prior section established that price-distance gradients for both business district and subway access became steeper following the road rationing policy. We now explore whether gentrification is a potential mechanisms driving these price effects. This is an empirical question: lower income groups may continue to outbid the rich for locations proximate to the $\mathrm{CBD}$ and subway stations if developers supply smaller housing units with a higher price per square meter. If the road rationing policy is more binding for the rich relative to the poor, Eq. 6 and Eq. 7 are less likely to hold and the average income of households proximate to either the CBD and subway stations will increase.

Figures 11 and 12 show estimates of $\alpha_{q}$ from Eq. 9. Each are generally consistent with the model's prediction: wealthier (poorer) households move closer to (further from) both subway stations and CBD relative to lower (higher) income households after the road rationing policy. Zip code level fixed effects allow us to examine how income changes within a neighborhood over time.

In Figure 11, the outcome variable of interest is distance to the nearest CBD. We show the event study using our main specification of Eq. 9 in the darker shade, as well as a specification with fixed effects for the line of the housing unit's nearest subway station in lighter gray. Accessibility to the CBD will differ across subway lines: lines leading out to airports (the Daxing Airport Express or the Capital Airport Express lines) or radial lines along Beijing's perimeter (e.g., lines 15 or 9) will be less useful for accessing jobs in one of Beijing's CBD relative to the circular lines (e.g., lines 10 and 2) or the east-west lines (eg., lines 1 and 6) that traverse several economically important parts of the Beijing. Comparing specifications on sorting near the CBD with versus without the subway line fixed effects sheds light on the mechanism driving our results.

In both specifications, the difference in CBD proximity across the income distribution is generally stable, and not statistically different from the CDR quarter in periods prior to July of 2008. The two quarters prior to the CDR policy exhibit some pre-trends, suggesting that higher income individuals were more likely to move to locations closer to CBD relative to lower income groups before the CDR policy went into effect. The Beijing government enacted a trial period in late 2007 and Beijing news media covered stories on the coming road rationing during the first quarter of 2008. Consequently, it is possible that these pre-trends reflect adjustment to new information on the road rationing policy. Indeed, Google Search trends in Appendix Figure A3 suggest individuals may have 
anticipated the policy in late 2007 and early 2008.

Figures 11 shows that when employing variation across subway lines (by excluding subway line fixed effects), there is a significant change in the income-business district proximity gradient. After the road rationing policy, the composition of wealth increases (falls) in areas proximate to (far from) CBD. Comparing two households of different income, the household that is $10 \%$ wealthier than another household is likely to live 0.4 to 0.6 percentage points (or about 0.6 to 1 kilometer) closer to the nearest central business district after the road rationing relative to the poorer household. However, after conditioning on variation in the income-distance gradient within a subway line, there is no significant difference after the CDR policy relative to before. This suggests that individuals demand locations proximate to the $\mathrm{CBD}$ in so far as those locations increase access to CBD. Holding the distance to the nearest subway station fixed, additional subway stops likely have a trivial effect on total commute times. But commute times may differ substantially across subway lines depending on how linked that line is to jobs. Our results are consistent with this hypothesis.

Table 4 shows the mean change in the income-business district proximity gradient comparing 24 months before versus 24 months after the CDR policy. The level estimate on household income is negative, suggesting that higher income households are more likely to live proximate to CBD (consistent with Panel A of Figure 7). The gradient becomes steeper after the policy, and is more than double the baseline gradient estimate in some specifications. Results in column (3) show that a household that is $10 \%$ wealthier (poorer) is likely to locate 0.5 percentage points closer to (further from) the nearest business district after the CDR compared to before. Conditioning on variation within a particular subway line in columns (4) and (5) reduces the estimate magnitude substantially, and the coefficient is no longer statistically significant. These results are similar after employing alternate definitions of the Beijing CBD, as shown in Appendix Table A3.

We show changes in the income-subway proximity gradient over time in Figure 12. Again, using only variation across households proximate to the same subway line to estimate the gradient shift renders different results than allowing for comparisons of households across subway lines. Our results suggest that not all subway stations are valued equally. The gray dots show estimates of $\alpha_{q}$ in Eq. 9 that exclude subway line fixed effects: there is no noticeable income-based sorting proximate to stations. However, after removing variation across households driven by the connectivity of their nearest subway line to areas of Beijing (darker red dots), there does appear to be a trend break: higher income households differentially sort near subway stations. The gradient shift estimate is small 
and statistically insignificant in the quarters immediately following the CDR, but becomes marginally significant and larger in magnitude after the second quarter of 2010. In both specifications, there is no significant evidence that higher income households differentially sort near subway stations in periods leading up to the CDR policy.

Table 5 shows the average difference-in-difference estimate of the CDR effect on the incomesubway proximity gradient. In columns (4) and (5) where we employ the most restrictive controls, the results show that a household with $10 \%$ higher (lower) in income is likely to live 0.8 percentage points closer (further) from the nearest subway station after the CDR relative to before the policy. Given the mean household income and subway proximity in our sample, these estimates imply that a household earning 730 yuan less per month (or about $\$ 1,200$ per year) will live approximately 0.1 kilometer further from a subway station following the road rationing policy.

While these results on demographic shifts are economically small, they explain approximately $30 \%$ of the overall increase from 2006 to 2010 in the elasticity of distance with respect to income. ${ }^{19}$ This suggests that city-wide policies aimed at reducing traffic and air pollution can be potentially regressive because they not only increase the premium for center-city locations, but they also increase competition for housing near public transit, the mode choice disproportionately utilized by lower income groups. In absence of Beijing's aggressive subway investments, the housing market and demographic sorting responses would likely be stronger.

The potential regressivity of a city-wide road rationing policy will depend upon the level of enforcement and the potential for behavioral adjustments. For example, if the purchase of new cars in Beijing were unregulated, wealthy car drivers could have circumvented the license-plate based road rationing by purchasing a second car, as in the case of Mexico City (Davis 2008). Such offsetting behavior would likely mitigate the road rationing policy's effect on the housing market and demographic sorting. Beijing's strong compliance rate means that car owners can only adjust through a combination of using public transit and relocating within the city to reduce their total commute time.

\subsection{Robustness Checks}

The government of Beijing has invested heavily in expanding its subway network since 2000. As of 2000, Beijing had two subway lines with 31 stations while today the city has 21 lines with over 370

\footnotetext{
${ }^{19}$ As of 2006 , the elasticity of distance to the CBD (subway) with respect to income was approximately -0.62 (-0.77). As of 2010, the elasticity of distance to the distance to the CBD (subway) with respect to income was approximately -0.77 (-1.05). We calculate these using cross sectional regressions of $\ln$ (distance) as a function of $\ln$ (household income) with year-by-month fixed effects.
} 
stations. Appendix Figure A1 shows how the subway network has expanded substantially over the last two decades, particularly since 2010. The placement of new lines and stations is unlikely to be random. To the extent that increased subway proximity over time is correlated with other location attributes that affect housing prices, such as expectations on commercial development, our results on the subway proximity-price premium may be spurious. Similarly, reverse causality may occur if new subway stations open in areas with increasing wealth.

We address these concerns in several ways. First, we test whether subway stations are more likely to open in gentrifying neighborhoods relative to stagnant, or declining neighborhoods. In Appendix Figure A8, we find the population weighted mean of household income by jiedao in each quarter-of-year and compare changes in mean income across quarters leading up to and following the opening of a subway station in that jiedao. There is no evidence of a significant upward trend in household income preceding the opening date of a station, suggesting that across Beijing, siting of new stations is not directly correlated with income growth, consistent with Li et al. (2016).

We next exclude housing units that experienced subway station development nearby. For this sensitivity check, our sample includes only housing units that maintained the same distance to their nearest subway station from 2005 through 2016. Approximately 1,200 building complexes in our sample met this criteria, leaving about $50 \%$ of all transaction observations. Relying purely on timeseries variation, rather than spatial variation in subway expansion, results of the bid-rent gradient shift for subway proximity are consistent with our main results. The bid-rent gradient in Appendix Figure A9 demonstrates a substantial tilt following the road rationing policy. Appendix Table A4 shows estimates of the subway proximity-price gradient for this restricted sample. The gradient change is attenuated but within a standard deviation of our main results in Table 3. For housing units with no change in their proximity to the nearest subway station, the road rationing policy increased the premium for these units by an additional $1.2 \%$ per kilometer compared to $3.5 \%$ estimated from our full sample in Table 3 (based on column (4) of both tables). We interpret these results as a lower bound on the increased demand for subway proximity. The subway stations near this housing subsample are some of the oldest lines and stations in the system network (Beijing's oldest lines were built in 1969 and 1971, without substantial additions until the mid-2000's) thus proximity to these areas may be less desirable to the extent that these lines offer less network advantages and may run less efficiently compared to the newer lines.

Lastly, we conduct two placebo analyses. First, we test whether areas that received future sub- 
way development after our study period experienced differential price trends over time. In Appendix Figure A10, we estimate the effect of subway proximity among a sample of housing units that were outside of walking distance from a subway station up through 2013, but came to be within 3 kilometers after new stations were built after 2013. This sample is a subset of housing units located in areas that received development in the future, but should not be affected by the road rationing policy during our study period because they are not within reasonable walking distance of subway stations. Any price effects from the policy would raise concern that correlated shocks stemming from unobserved economic investment or growth caused the subway proximity-price gradient shift, as opposed to increased demand for the subway itself. Appendix Figure A10 is suggestive that the road rationing policy did not significantly increase the price premium for subway proximity among this group of housing units. The point estimates are imprecisely estimated due to smaller sample sizes in the post-CDR period. However, the quarterly estimates do not show a clear upward trend, as in Figure 9.

Our second and final placebo analysis tests whether the CDR adjusts prices or the spatial distribution of wealth in areas close to undesirable locations of the city. This test informs whether we are justified in interpreting our main results as a consequence of people's desire to reduce commuting costs. A restriction on traveling by car during the week should not affect the (un)desirability of proximity to major pollution sites.

We obtained data on major sources of pollution throughout Beijing as of 2006 and 2007 from the emissions monitoring program of the Ministry of the Environmental Protection. These data provide the location and emissions level of industrial pollution sources. We isolated firms in the top 10th percentile of total air discharge, and geocoded their locations. We then estimate the same hedonic and sorting specifications based on Eqs. 9 and 8, respectively. Some major pollution sources are also major employment locations. Unfortunately, we are unable to observe employment associated with the pollution sources. To ensure that we do not conflate commuting effects with the dis-amenity effects of pollution sites, we restrict our sample of pollution sites to those that are at least 3 kilometers away from a major central business district. This leaves a sample of 114 pollution sites throughout Beijing, out of a total of 449 sites. Appendix Figure A11 compares our main estimates on the price-distance gradient shifts for subway and CBD proximity shown in black to that of proximity to major pollution locations shown in gray. "M1" through "M6" denote various specifications of the hedonic regression. The placebo estimates are generally smaller in magnitude than our main hedonic estimates, and are statistically indistinguishable from zero. Appendix Figure A12 shows results of a similar exercise 
for income-sorting. Again, the placebo estimates (shown in gray) of the effect of the CDR on the elasticity of distance with respect to household income are statistically indistinguishable from zero. These findings demonstrate that price-distance gradients and income sorting did not change in all parts of the city after the CDR. Rather, the CDR increased desirability of areas that are most accessible to major employment centers of the city. ${ }^{20}$

\subsection{Sorting Mechanisms}

While the prior analysis documented how the CDR increased the price and mean household income of housing units close to economically important areas of Beijing, it is not clear whether these sorting effects are a result of displacement of poorer households, or gentrification and development of new housing. Evidence of displacement raises equity concerns for the incumbent households. We explore which mechanism explains the sorting results by testing first, whether total housing stock increased and second, whether the number of lower income households fell in absolute terms in areas proximate to subways and the CBDs over time.

We delineate "proximity" at 5 kilometers because this is the mean distance to the nearest CBD in our sample and because demand for subway proximity attenuates at this distance. By neighborhood, we count the number of newly built housing by month in locations within versus over 5 kilometers of subways and CBD. We then take the mean of new builds across neighborhoods, and plot these values by month in Figure 13. Panel A shows that new development increased after the CDR in areas within 5 kilometers of subway stations more so than areas over 5 kilometers from subway stations. Panel B shows that new development exhibited a similar upward trend in areas both close and far from Beijing's CBD. These figures suggest that housing supply adjusted to the increased demand for housing near city centers. This may explain why the price effects for proximity (show in Figure 8 and 9) reverted to pre-CDR levels in the three years following the CDR.

We repeat this non-parametric approach in Panels $\mathrm{C}$ and $\mathrm{D}$ with a focus on count of high relative to low income households. We first look only at households living within 5 kilometers of either subway stations or CBD. We then divide this sub-sample into households above median versus below median income, where the median is calculated using the pre-CDR distribution from January 2005 through July 2008. We count the number of households in each income category by neighborhood, and plot the count changes over time. Panels C and D show a clear upward trend in the number of higher income

\footnotetext{
${ }^{20}$ Using similar housing transactions data and the geocoded major polluters in Beijing, Barwick et al. (2019) show that the price-distance gradient with respect to the nearest major polluter became steeper after the national pollution monitoring and information disclosure program that rolled out in three waves across cities starting from 2013.
} 
households in proximate locations, whereas the count of lower income households stays relatively flat. Based on the data patterns in these figures, it does not appear that lower income households were displaced from proximate locations. Instead, these patterns are suggestive that newly-built housing in desirable areas of Beijing are occupied by higher income households.

\section{Conclusion}

Road rationing policies are an increasingly common policy instrument used among major cities to reduce traffic congestion and air pollution. While prior work has investigated the effectiveness of these policies at improving air quality and congestion, less is known about the ramifications of these policies on the residential location decisions and urban spatial structure.

Urban land use theory provides clear predictions on how such policies could impact the housing market and the sorting of demographic groups relative to one another. This paper uses detailed, microlevel data on home purchases and buyer demographics in combination with a city-wide road rationing to test these theories in the context of Beijing, China. Our analysis relies on fine-scale spatial fixed effects to control for location-specific correlates of public transit. We find that the road rationing policy required prospective home-buyers to pay an additional $\$ 3,000$ on average for a one-kilometer reduction in distance to a subway station. The premium for central business district proximity also increased, but by a smaller magnitude of approximately $\$ 1,000$ per kilometer. Considering that the average Beijing household earns approximately $\$ 12,000$ (86,000 yuan) per year, these effect sizes are economically large. We additionally utilize novel micro data on household income and housing locations to explore how the road rationing policy impacted the residential location choices of different income groups. Following the policy-induced shocks to housing prices, the composition of households living close to subway stations as well as close to Beijing's CBDs shifted toward wealthier households. These results are consistent with the predictions of our theoretical model based on LeRoy and Sonstelie (1983).

These results provide some suggestive evidence that city-wide road rationing policies can have the unintended consequence of limiting access to public transit for lower income individuals. Such effects are likely to be stronger in markets where car ownership is cost-prohibitive to the poor and when enforcement of road rationing is strict. Our findings expose several important avenues for future research: first, the welfare implications of road rationing policies are not clear and will depend upon how commute times and exposure to pollution change among the wealthy relative to the poor. Such analysis can inform whether rent stabilization or a welfare transfer process may be necessary to offset impacts of road rationing policies on housing affordability. Second, how might a market- 
based instrument such as congestion pricing affect household location decisions and urban spatial structure relative to a road rationing policy? Understanding the welfare impacts and the distributional consequences of market-based versus command-and-control approaches warrants future research. 


\section{References}

Alonso, W. (1964). Location and land use. Toward a general theory of land rent. Cambridge, Mass.: Harvard Univ. Pr.

Barahona, N., Gallego, F., Montero, J.-P., et al. (2018). Vintage-specific driving restrictions. Review of Economic Studies.

Barwick, P. J., Li, S., Lin, L., and Zou, E. (2019). From fog to smog: The value of pollution information. Working Paper.

Baum-Snow, N. and Kahn, M. E. (2000). The effects of new public projects to expand urban rail transit. Journal of Public Economics, 77(2):241-263.

Beijing Transport Institute (2010). Beijing transport annual report. http://www.bjtrc.org.cn/ JGJS . aspx?id=5 . 2\&Menu=GZCG. Accessed: 2019-03-2 .

Billings, S. B. (2011). Estimating the value of a new transit option. Regional Science and Urban Economics, 41(6):525-536.

Brueckner, J. K. and Rosenthal, S. S. (2009). Gentrification and neighborhood housing cycles: will america's future downtowns be rich? The Review of Economics and Statistics, 91(4):725-743.

Brueckner, J. K., Thisse, J.-F., and Zenou, Y. (1999). Why is central paris rich and downtown detroit poor?: An amenity-based theory. European economic review, 43(1):91-107.

Carrillo, P. E., Malik, A. S., and Yoo, Y. (2016). Driving restrictions that work? quito's pico y placa program. Canadian Journal of Economics/Revue canadienne d'économique, 49(4):1536-1568.

Chen, Y., Jin, G. Z., Kumar, N., and Shi, G. (2013). The promise of beijing: Evaluating the impact of the 2008 olympic games on air quality. Journal of Environmental Economics and Management, 66(3):424-443.

Davis, L. W. (2008). The effect of driving restrictions on air quality in mexico city. Journal of Political Economy, 116(1):38-81.

Duranton, G. and Puga, D. (2015). Urban land use. In Handbook of regional and urban economics, volume 5, pages 467-560. Elsevier.

Eskeland, G. S. and Feyzioglu, T. (1997). Rationing can backfire: the "day without a car" in mexico city. The World Bank Economic Review, 11(3):383-408.

Fang, H., Gu, Q., Xiong, W., and Zhou, L.-A. (2016). Demystifying the chinese housing boom. NBER macroeconomics annual, 30(1):105-166.

Gallego, F., Montero, J.-P., and Salas, C. (2013). The effect of transport policies on car use: Evidence from latin american cities. Journal of Public Economics, 107:47-62. 
Gibbons, S. and Machin, S. (2005). Valuing rail access using transport innovations. Journal of urban Economics, 57(1):148-169.

Gin, A. and Sonstelie, J. (1992). The streetcar and residential location in nineteenth century philadelphia. Journal of Urban Economics, 32(1):92-107.

Glaeser, E. L., Kahn, M. E., and Rappaport, J. (2008). Why do the poor live in cities? the role of public transportation. Journal of urban Economics, 63(1):1-24.

Gu, Y., Deakin, E., and Long, Y. (2017). The effects of driving restrictions on travel behavior evidence from beijing. Journal of Urban Economics, 102:106-122.

Hooker, J. (2008). Beijing announces traffic plan for olympics. The New York Times.

Jain, P. (2018). Delhi pollution: Vehicles, not stubble burning, main cause, says teri study. India Today.

Lee, S. and Lin, J. (2017). Natural amenities, neighbourhood dynamics, and persistence in the spatial distribution of income. The Review of Economic Studies, 85(1):663-694.

LeRoy, S. F. and Sonstelie, J. (1983). Paradise lost and regained: Transportation innovation, income, and residential location. Journal of Urban Economics, 13(1):67-89.

Li, S. (2018). Better lucky than rich? welfare analysis of automobile license allocations in beijing and shanghai. Review of Economic Studies, 85(4):2389-2428.

Li, S., Yang, J., Qin, P., and Chonabayashi, S. (2016). Wheels of fortune: Subway expansion and property values in beijing. Journal of Regional Science, 56(5):792-813.

Lu, X. (2018). Housing markets and automobile policy. Manuscript.

Margo, R. A. (1992). Explaining the postwar suburbanization of population in the united states: The role of income. Journal of urban economics, 31(3):301-310.

Mills, E. S. (1967). An aggregative model of resource allocation in a metropolitan area. The American Economic Review, 57(2):197-210.

Muth, R. F. (1967). The distribution of population within urban areas. In Determinants of Investment Behavior, pages 271-299. NBER.

Redding, S. J. and Turner, M. A. (2015). Transportation costs and the spatial organization of economic activity. In Handbook of regional and urban economics, volume 5, pages 1339-1398. Elsevier.

Rosen, S. (1974). Hedonic prices and implicit markets: product differentiation in pure competition. Journal of political economy, 82(1):34-55.

Severen, C. (2018). Commuting, labor, and housing market effects of mass transportation: Welfare and identification. FRB of Philadelphia Working Paper. 
Small, K. A. (2012). Valuation of travel time. Economics of transportation, 1(1):2-14.

Sun, W., Zheng, S., Geltner, D. M., and Wang, R. (2017). The housing market effects of local home purchase restrictions: evidence from beijing. The Journal of Real Estate Finance and Economics, $55(3): 288-312$.

Tang, M. and Coulson, N. E. (2017). The impact of china's housing provident fund on homeownership, housing consumption and housing investment. Regional Science and Urban Economics, 63:25-37.

Tsivanidis, N. (2019). The aggregate and distributional effects of urban transit infrastructure: Evidence from bogotá's transmilenio. Unpublished manuscript.

U.S. Census (2019). Median sales price for new houses sold in the united states. https://fred. stlouisfed.org/series/MSPNHSUS. Accessed: 2019-03-2.

Viard, V. B. and Fu, S. (2015). The effect of beijing's driving restrictions on pollution and economic activity. Journal of Public Economics, 125:98-115.

Wolff, H. (2014). Keep your clunker in the suburb: Low-emission zones and adoption of green vehicles. The Economic Journal, 124(578):F481-F512.

World Health Organization (2019). Public health, environmental and social determinants of health. https://www.who.int/phe/health_topics/outdoorair/databases/cities/en/. Accessed: 2019-03-31.

Xu, Y., Zhang, Q., and Zheng, S. (2015). The rising demand for subway after private driving restriction: Evidence from beijing's housing market. Regional Science and Urban Economics, 54:28-37.

Zhang, W., Lawell, C.-Y. C. L., and Umanskaya, V. I. (2017). The effects of license plate-based driving restrictions on air quality: Theory and empirical evidence. Journal of Environmental Economics and Management, 82:181-220. 
Figure 1: Global Growth in Urban Road Rationing Policies

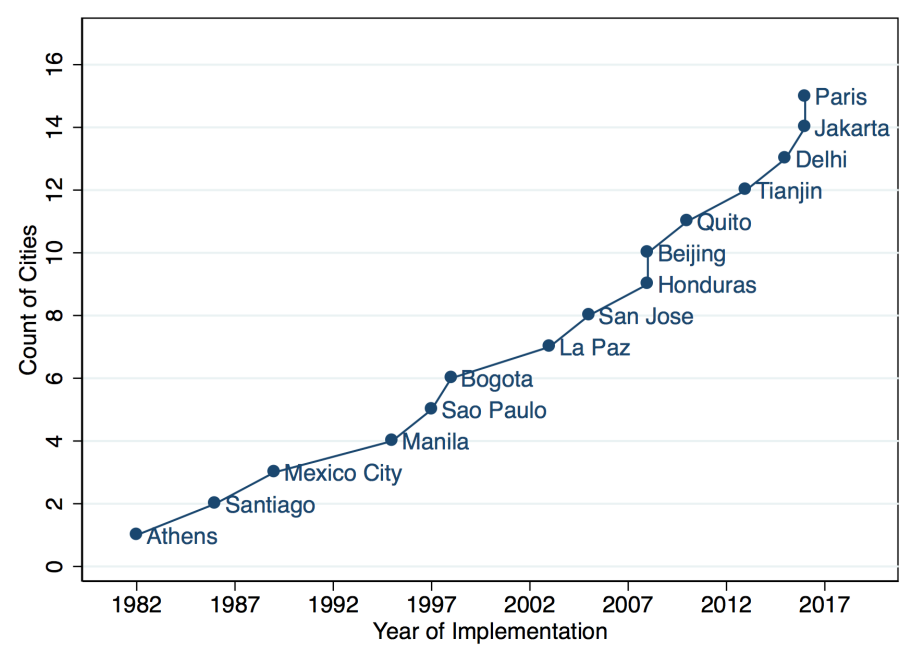

Sources: ChinaDaily.com ( http://www.chinadaily.com.cn/china/2013-12/16/content_17175846.htm); BBC.com (https://www.bbc.com/news/world-europe-38236926); and Wikipedia article on "Roat Space Rationing" ( https: //en.wikipedia.org/wiki/Road_space_rationing)

Figure 2: Transit Mode Choice by Income

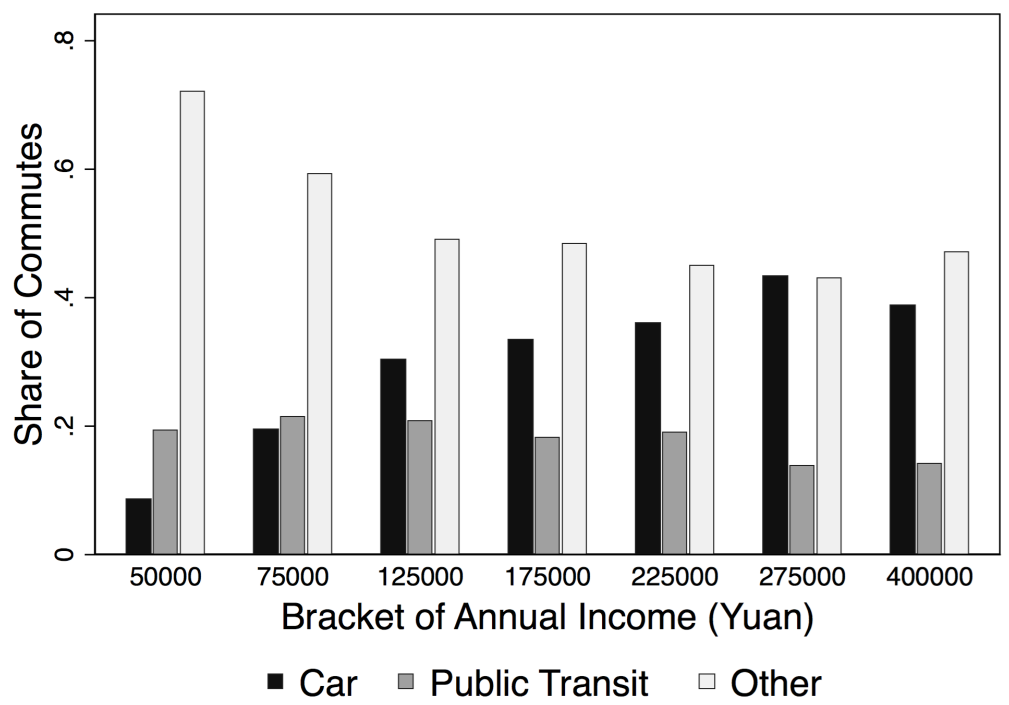

Note: Data sourced from 2010 Beijing Household Travel Survey (Beijing Transport Institute 2010). Based on 276,377 responses. "Other" includes walking, cycling, taxi, company shuttle, mixed modes. 
Figure 3: Housing Units \& Subway Stations in Beijing

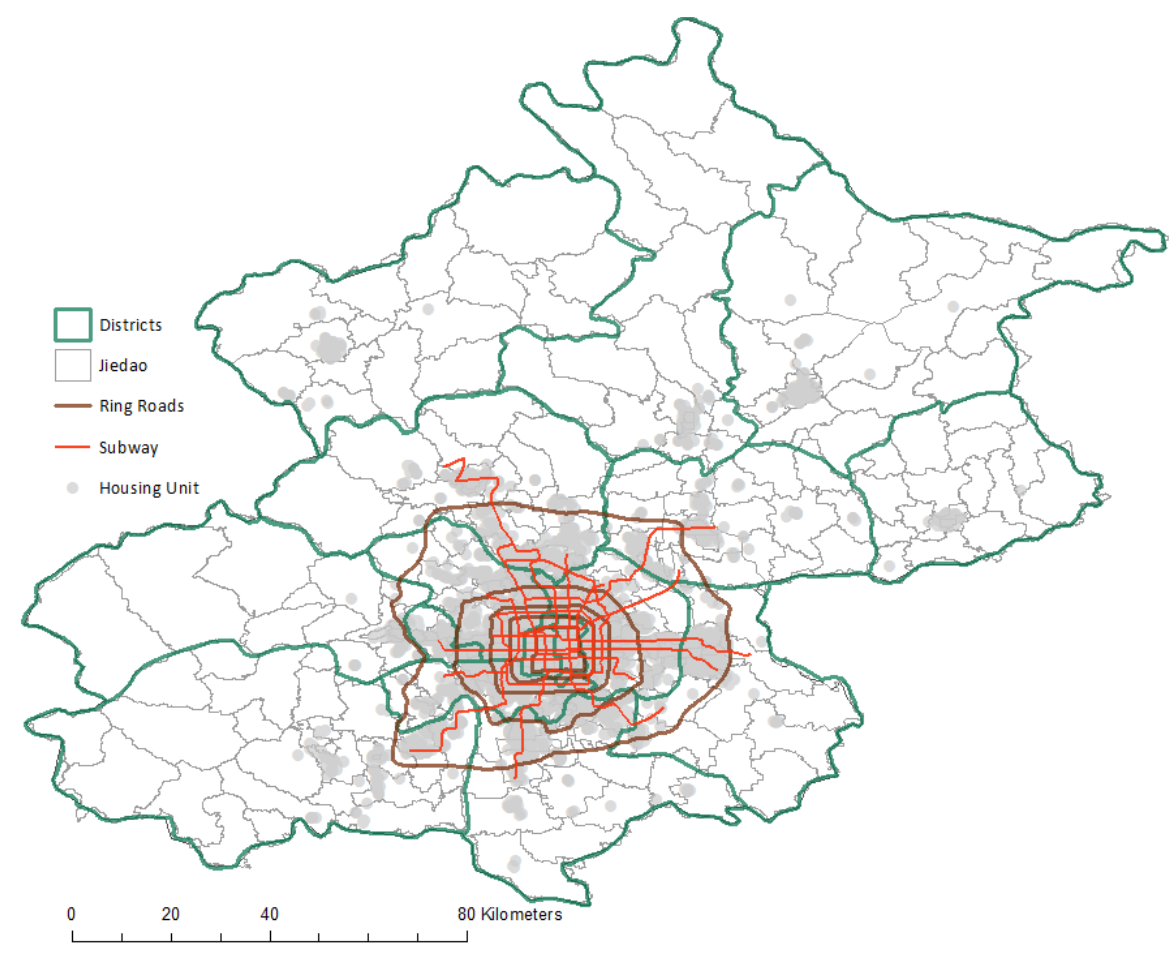

Note: Figure shows the location of housing units purchased between 2005-2014 throughout Beijing. Source: Beijing Real estate data.

Figure 4: Business Districts of Beijing

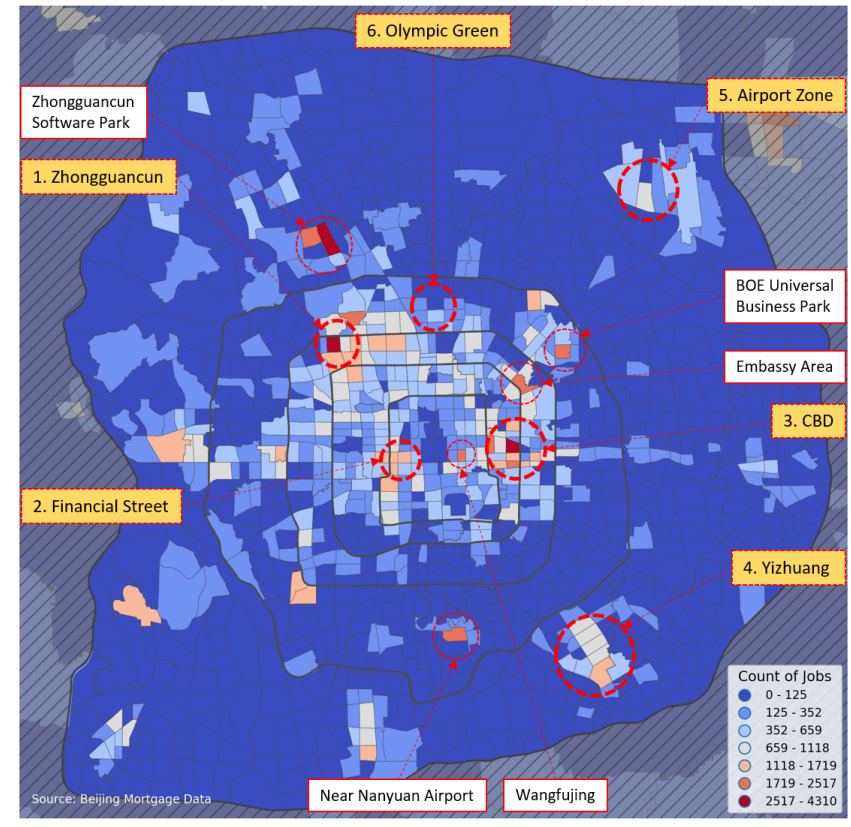

Note: Figure shows employment concentration by transportation analysis zone. Employment location data sourced from mortgage application data. See Section 2 for details. 
Figure 5: Neighborhood Variation
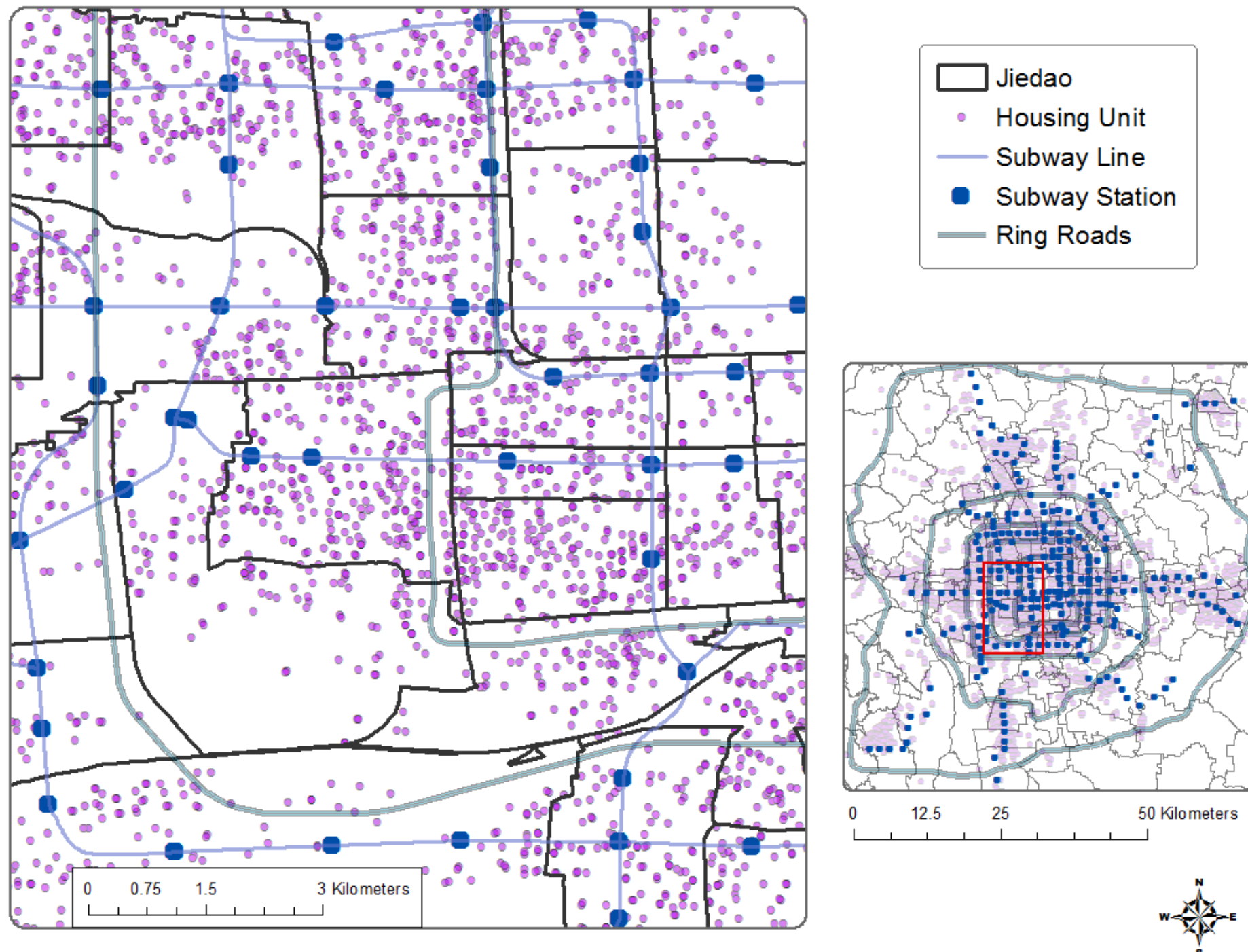

Sources: Beijing Real estate data; mortgage application data. Figure shows a southwest section of central Beijing, between the second and third ring roads. CDR effects are identified based off of variation in distance to subway stations, or distance to the nearest CBD across housing units within a jiedao. 
Figure 6: Price Proximity Gradient
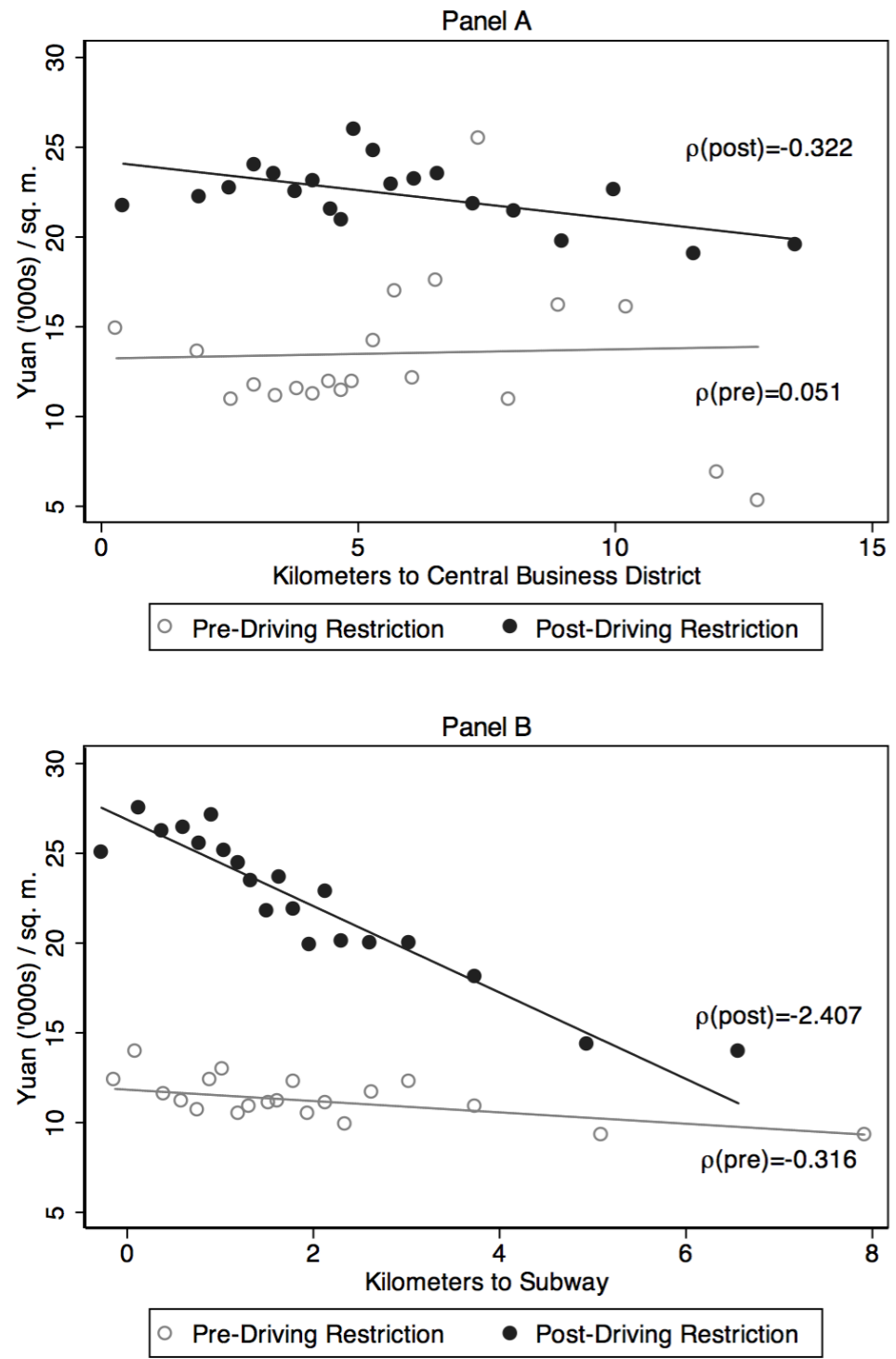

Note: Figures plot mean house price for each of 20 distance bins. Each dot represents 6,300 and 12,900 obs per bin in pre and post, respectively. Panel A means are residualized by distance to the nearest subway. Panel B means are residualized by distance to the central business district. "Central Business District" defined as the closest of 7 main business districts. $\rho$ (pre) and $\rho$ (post) are regression coefficients. Includes years 2005-2014. Source: Real estate transaction dataset. 
Figure 7: Income Proximity Gradient
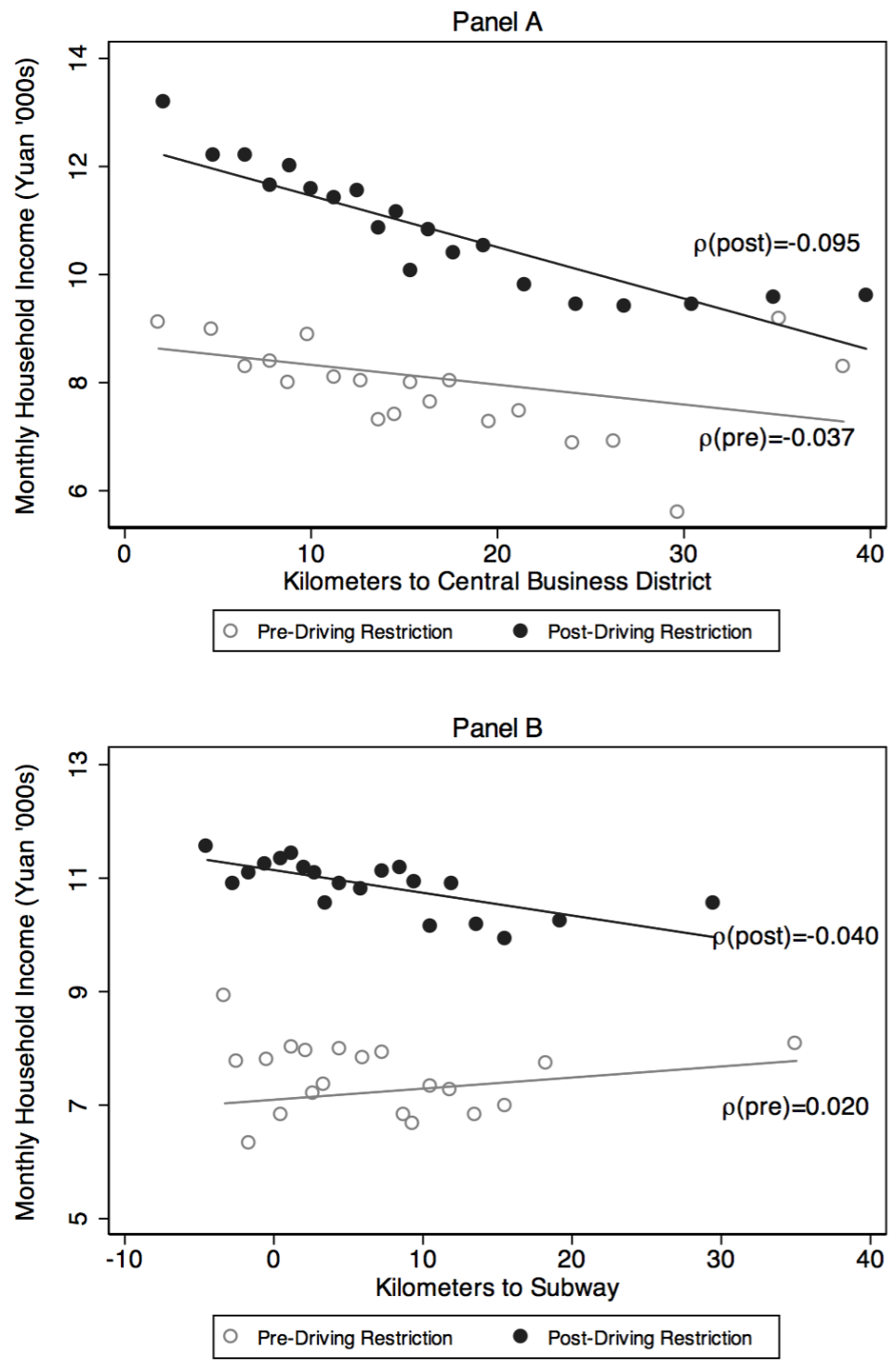

Note: Figure plots mean household income for each of 20 distance bins. Each dot represents 850 and 3670 obs per bin in pre and post, respectively. Panel A means are residualized by distance to the nearest subway. Panel B means are residualized by distance to central business district. "Central Business District" defined as the closest of 7 main business districts. $\rho$ (pre) and $\rho$ (post) are regression coefficients. Includes years 2005-2014. Source: Mortgage application dataset. 
Figure 8: Event Study of the CBD Distance-Housing Price Premium

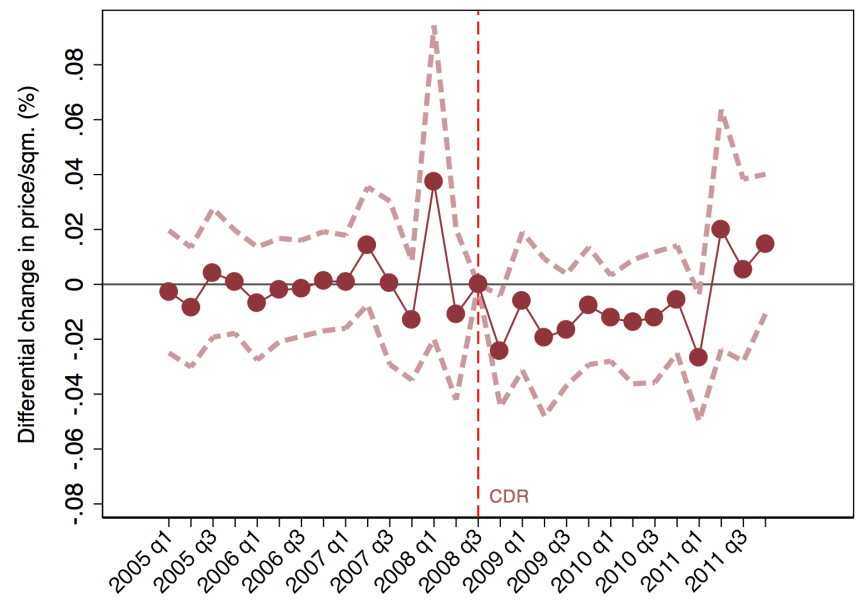

Note: Figure shows the partial effect of distance to central business district on housing price $\ln$ (total price/sqm in $¥ 2007$ ) at each quarter between Jan 2005 and Dec 2011. The omitted quarter is July-October 2008. Sample includes 322,686 transactions. Controls include fixed effeects for unit type (resale or newsale), jiedao, and year-quarter; as well as controls for distance to subway, age, age ${ }^{2}$, size, floor-area ratio, green space, property management fee, parking fee, number of housing units and building units in complex, and unit size. Standard errors clustered at jiedao level. "CBD" (Central Business District) defined as the closest of 7 main business districts. Sample restricted to units located within $10 \mathrm{~km}$ of their closest CBD.

Figure 9: Event Study of the Subway Distance-Housing Price Premium

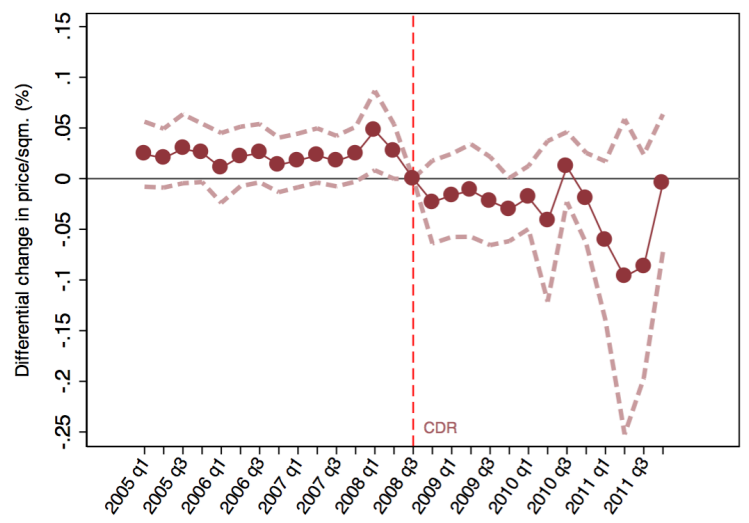

Note: Figure shows the partial effect of subway distance on housing price $\ln$ (total price/sqm in $¥ 2007$ ) at each quarter between Jan 2005 and Dec 2011. The omitted quarter is July-October 2008. Sample includes 256,149 transactions. Controls include fixed effects for unit type (resale or newsale), jiedao and year-quarter; as well as controls for distance to nearest CBD, age, age ${ }^{2}$, size, floor-area ratio, green space, property management fee, parking fee, number of housing units and building units in complex, and unit size. Standard errors clustered at jiedao level. 
Figure 10: Average Effect of road rationing on Housing Prices by Subway Distance Bin

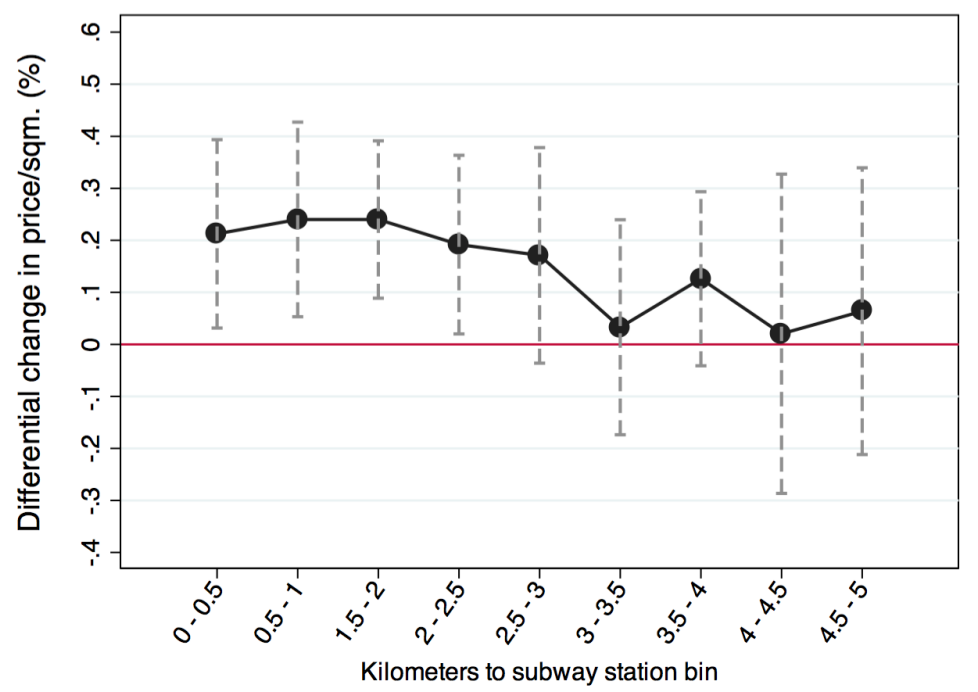

Note: Figure plots $\alpha_{b}$, estimates of the average change in housing price per square meter (y) following the CDR by half-mile distance bins to subway stations $\left(I_{b}\right): y_{i j t}=\sum_{b} \alpha_{b}\left(I_{b} \times C D R_{t}\right)+\sum_{b} \kappa_{b}\left(I_{b}\right)+\rho C D R_{t}+\mathbf{X}_{i j t} \theta+\gamma_{j}+\tau_{t}+\varepsilon_{i j t}$. The reference bin includes housing units over 5 kilometers from subway stations. Dashed lines represent $95 \%$ confidence intervals. Includes transactions from July 2006 through July 2010. Controls (X) include fixed effects for unit type (resale or newsale), jiedao $\left(\gamma_{j}\right)$, year, month of transaction $(\tau)$, total number of floors in building, decoration level, whether at top floor, and facing direction; as well as controls for age, age ${ }^{2}$, size, floor-area ratio, green space, number of housing units and building units in complex, and unit size. Standard errors clustered at jiedao level. 
Figure 11: Event Study of the Income-CBD Distance Gradient

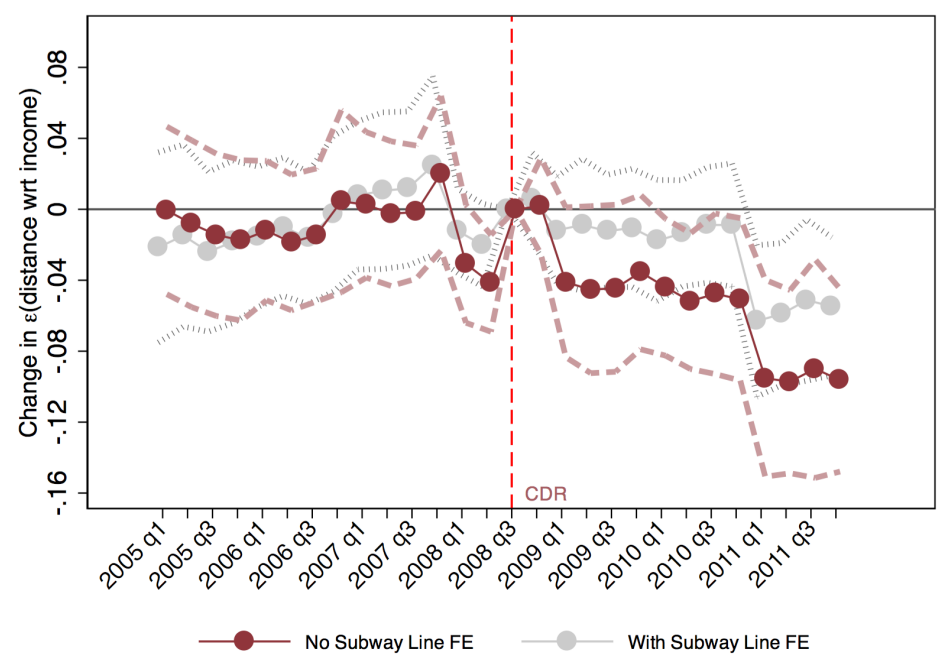

Note: Figure shows the partial effect of income on distance to CBD at each quarter between January 2005 and December 2011. The omitted quarter is July-October 2008. Controls include fixed effects for year, month, neighborhood, age, rank, education, and experience of buyers, and a control for distance to nearest subway station. Grey denotes a specification that includes fixed effects for the subway line associated with the housing unit's nearest subway station. Standard errors clustered by zip code.

Figure 12: Event Study of the Income-Subway Distance Gradient

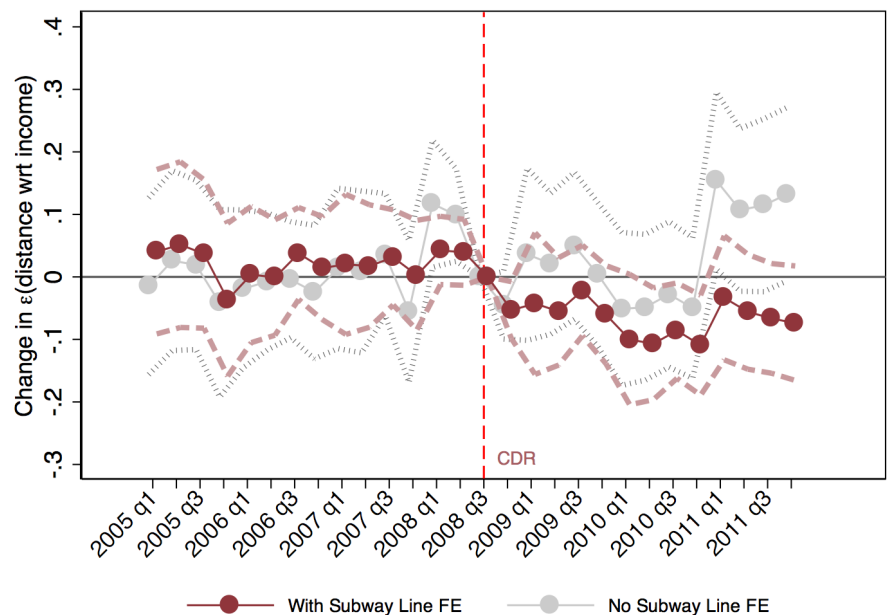

Note: Figure shows the partial effect of income on distance to the nearest subway station at each quarter between January 2005 and December 2011. The omitted quarter is July-October 2008. Includes FE for year, month, neighborhood, age, rank, education, and experience of buyers, the subway line associated with the housing unit's nearest subway station, and a control for distance to nearest CBD. Grey denotes a specification that excludes the subway line fixed effects. Standard errors clustered by zip code. 
Figure 13: Supply of New Housing and road rationing

A. New Builds by Subway Proximity

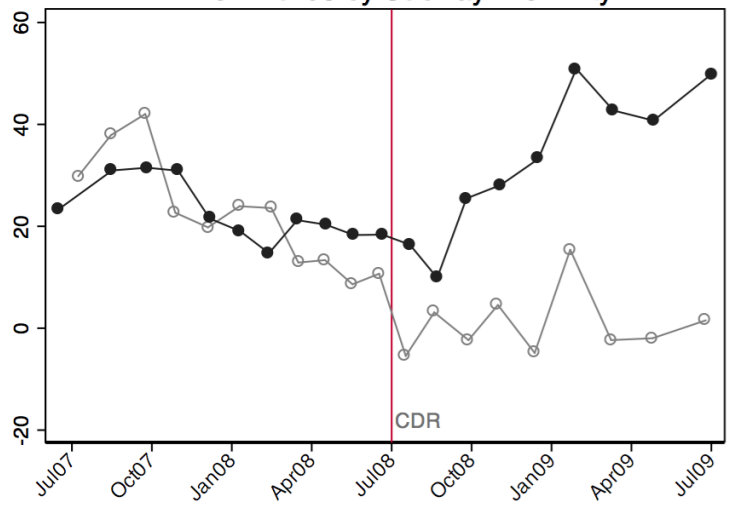

B. New Builds by CBD Proximity

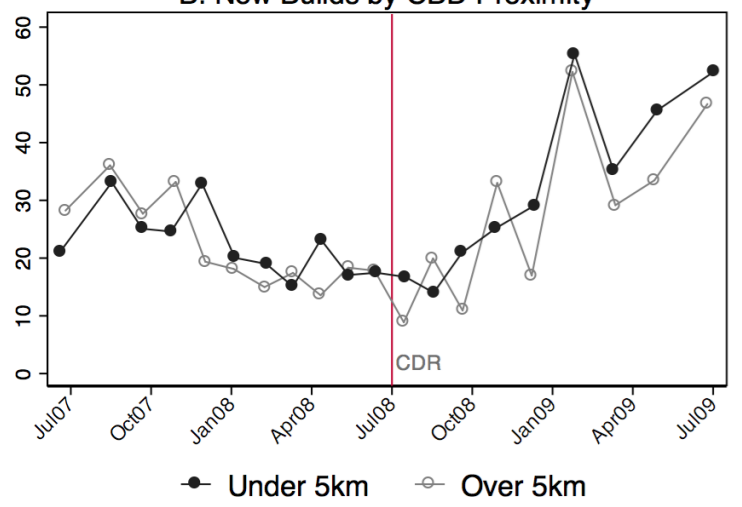

C. Households within $5 \mathrm{~km}$ of Subway by Income

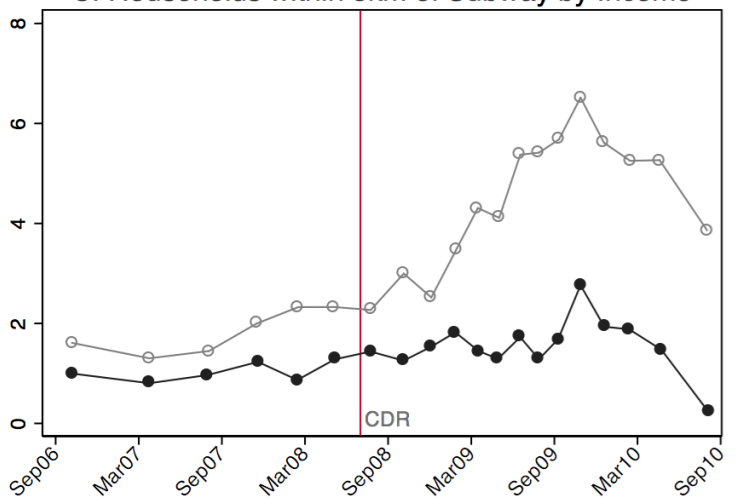

D. Households within $5 \mathrm{~km}$ of CBD by Income

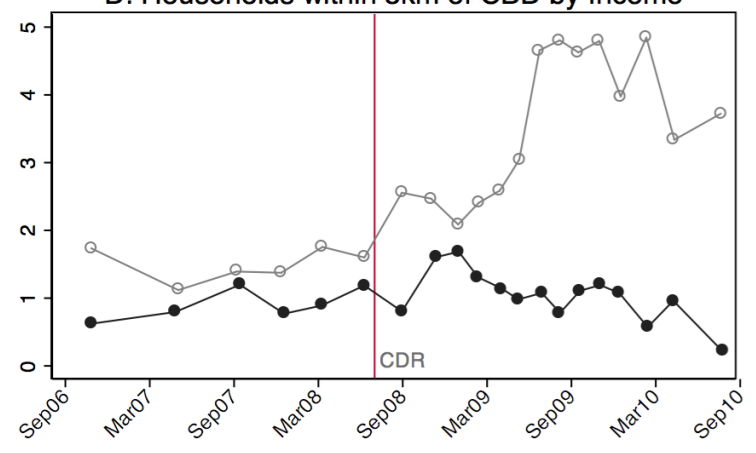

- Below Median Income a Above Median Income

Note: Panels (A) and (B) plot the mean new supply of housing by month for units under versus over $5 \mathrm{~km}$ of subway stations and the CBD, respectively. Sourced from the real estate transaction dataset. Panles (C) and (D) plot mean number of households living within $5 \mathrm{~km}$ of both Subway stations and the nearest central business district by income group. Median income is based on the pre-CDR income distribution and is calculated from all mortgage applications occuring from January 2005 through July 2008. Sourced from the mortgage application dataset. Means in all panels residualzed by neighborhood fixed effects. 
Table 1: Pre-CDR Descriptive Statistics

\begin{tabular}{|c|c|c|c|c|}
\hline & \multicolumn{2}{|c|}{ Real Estate Transactions } & \multicolumn{2}{|c|}{ Mortgage Data } \\
\hline & Mean & (St. Dev) & Mean & (St. Dev) \\
\hline Total purchase price ('07 Yuan) & $1,491,405.7$ & $1,090,428.9$ & $599,805.8$ & $303,918.9$ \\
\hline Price per sq.m & $13,274.5$ & $4,763.8$ & $6,225.8$ & $2,805.9$ \\
\hline Unitsize (sq.m.) & 107.8 & 48.7 & 100.6 & 33.3 \\
\hline Km to subway & 3.3 & 2.7 & 15.2 & 14.7 \\
\hline $\mathrm{Km}$ to nearest $\mathrm{CBD}$ & 6.1 & 3.9 & 20.5 & 14.6 \\
\hline Km to City Center & 9.2 & 3.7 & 26.9 & 17.1 \\
\hline Building Age & 10.7 & 7.1 & 6.4 & 7.4 \\
\hline Building Floor-to-Area Ratio & 2.9 & 1.3 & 2.2 & 1.0 \\
\hline Building Green space ratio & 0.3 & 0.1 & 33.1 & 7.4 \\
\hline Household Monthly Income ('07 Yuan) & & & 7,723 & 4,502 \\
\hline Age of household head & & & 35.2 & 6.6 \\
\hline Years of work experience of household head & & & 13.4 & 7.8 \\
\hline Education level of household head (mode) & & & Bachlor's & \\
\hline No. Complexes & $4,403.0$ & & $3,971.0$ & \\
\hline No. Neighborhoods & 188.0 & & 183.0 & \\
\hline Observations (Transactions) & $252,426.0$ & & $46,471.0$ & \\
\hline & 1,926 & & 4,858 & \\
\hline & 61,348 & & 5,273 & \\
\hline & 47,837 & & 4,410 & \\
\hline & 24,759 & & 4,225 & \\
\hline & 65,513 & & 12,513 & \\
\hline & 34,859 & & 8,321 & \\
\hline & 16,184 & & 6,871 & \\
\hline
\end{tabular}

Note: The unit of observation for the Real Estate Transaction data is a housing purchase transaction. The means calculated in column (1) are calculated using pre-policy months July 2007 through July 2008. The unit of observation for the Mortgage Data is a mortgage loan application, or a household, equivalently. The means in column (3) are calculated using pre-policy months July 2006 through July 2008. 
Table 2: Effects of CDR policy on City Center-Price gradient

\begin{tabular}{|c|c|c|c|c|c|c|}
\hline & $(1)$ & $(2)$ & $(3)$ & $(4)$ & $(5)$ & (6) \\
\hline $\mathrm{Km}$ to $\mathrm{CBD} \times \mathrm{CDR}$ & $\begin{array}{l}-0.005 \\
(0.010)\end{array}$ & $\begin{array}{c}-0.014^{* *} \\
(0.007)\end{array}$ & $\begin{array}{c}-0.013^{* * *} \\
(0.005)\end{array}$ & $\begin{array}{c}-0.013^{* * *} \\
(0.005)\end{array}$ & $\begin{array}{c}-0.019^{* *} \\
(0.007)\end{array}$ & $\begin{array}{l}-0.002 \\
(0.004)\end{array}$ \\
\hline $\mathrm{Km}$ to $\mathrm{CBD}$ & $\begin{array}{c}-0.035^{\text {**** }} \\
(0.009)\end{array}$ & $\begin{array}{l}-0.005 \\
(0.017)\end{array}$ & $\begin{array}{c}0.012 \\
(0.017)\end{array}$ & $\begin{array}{c}0.010 \\
(0.016)\end{array}$ & $\begin{array}{c}0.015 \\
(0.016)\end{array}$ & \\
\hline Jiedao FE & & $\mathrm{Y}$ & Y & $\mathrm{Y}$ & $\mathrm{Y}$ & Y \\
\hline Controls & & & $\mathrm{Y}$ & $\mathrm{Y}$ & $\mathrm{Y}$ & $\mathrm{Y}$ \\
\hline Year-Month FE & & & & $\mathrm{Y}$ & & \\
\hline DistrictxYear-Month Trend & & & & & $\mathrm{Y}$ & \\
\hline Building Complex FE & & & & & & $\mathrm{Y}$ \\
\hline Avg Proximity Premium / Km & $\$ 425.59$ & $\$ 1187.01$ & $\$ 1141.44$ & $\$ 1079.57$ & $\$ 1601.99$ & $\$ 176.53$ \\
\hline Observations & 82002 & 82002 & 82002 & 82002 & 82002 & 81547 \\
\hline Adjusted $R^{2}$ & 0.184 & 0.513 & 0.609 & 0.619 & 0.614 & 0.827 \\
\hline
\end{tabular}

Note: Dependent variable is $\ln$ (total price per square meter in 2007 real Yuan). Standard errors clustered at jiedao level. Sample spans 12 mos. before and after CDR. All specifications include year and month fixed effects. Average price premium is evaluated at a unit size of $122 \mathrm{sqm}$, the size at the mean distance to the nearest business district ( 5 and $7 \mathrm{~km}$ ), and at a conversion rate of 6.95 yuan per USD. Controls include fixed effects for unit type (newsale vs resale), top floor, floor level, facing direction, no. bedrooms, decoration level, ownership type, and total number of floors in building. Continuous controls include distance to nearest subway station, age, age2, size, floor-area ratio, green space, property management fees, parking fees, and size, number of housing units and number of buildings of the complex. ${ }^{*} p<0.10,{ }^{* *} p<0.05,{ }^{* * *} p<0.01$

Table 3: Effects of CDR policy on Subway-Price gradient

\begin{tabular}{|c|c|c|c|c|c|c|}
\hline & $(1)$ & $(2)$ & $(3)$ & $(4)$ & $(5)$ & $(6)$ \\
\hline Km to Subway x CDR & $\begin{array}{c}-0.046^{* *} \\
(0.020)\end{array}$ & $\begin{array}{c}-0.044^{* * *} \\
(0.012)\end{array}$ & $\begin{array}{c}-0.040^{* * *} \\
(0.011)\end{array}$ & $\begin{array}{c}-0.035^{* * *} \\
(0.011)\end{array}$ & $\begin{array}{c}-0.038^{* * *} \\
(0.010)\end{array}$ & $\begin{array}{c}-0.026^{* *} \\
(0.012)\end{array}$ \\
\hline Km to Subway & $\begin{array}{c}-0.048^{* * *} \\
(0.014)\end{array}$ & $\begin{array}{c}-0.003 \\
(0.013)\end{array}$ & $\begin{array}{c}-0.018^{* *} \\
(0.009)\end{array}$ & $\begin{array}{c}-0.017^{* *} \\
(0.008)\end{array}$ & $\begin{array}{c}-0.018^{*} \\
(0.010)\end{array}$ & $\begin{array}{c}-0.014^{*} \\
(0.008)\end{array}$ \\
\hline Jiedao FE & & $\mathrm{Y}$ & $\mathrm{Y}$ & $\mathrm{Y}$ & $\mathrm{Y}$ & $\mathrm{Y}$ \\
\hline Controls & & & $\mathrm{Y}$ & $\mathrm{Y}$ & $\mathrm{Y}$ & $\mathrm{Y}$ \\
\hline Year-Month FE & & & & $\mathrm{Y}$ & & \\
\hline DistrictxYear-Month Trend & & & & & $\mathrm{Y}$ & \\
\hline Building Complex FE & & & & & & $\mathrm{Y}$ \\
\hline Avg Proximity Premium / Km & $\$ 3772.96$ & $\$ 3556.21$ & $\$ 3256.27$ & $\$ 2877.02$ & $\$ 3079.41$ & $\$ 2127.93$ \\
\hline Observations & 82002 & 82002 & 82002 & 82002 & 82002 & 81547 \\
\hline Adjusted $R^{2}$ & 0.161 & 0.517 & 0.612 & 0.621 & 0.615 & 0.829 \\
\hline \multicolumn{7}{|c|}{$\begin{array}{l}\text { Note: Dependent variable is } \ln \text { (total price per square meter in } 2007 \text { real Yuan). Standard errors clustered at jiedao level. } \\
\text { Sample spans } 12 \text { mos. before and after CDR. All specifications include year and month fixed effects. Average price premium } \\
\text { is evaluated at a unit size of } 115 \mathrm{sqm} \text {, the size at the mean distance (between } 2 \text { and } 4 \mathrm{~km} \text { ) to the nearest subway station, and } \\
\text { at a conversion rate of } 6.95 \text { yuan per USD. Controls include fixed effects for unit type (newsale vs resale), top floor, floor level, } \\
\text { facing direction, no. bedrooms, decoration level, ownership type, and total number of floors in building. Continuous controls } \\
\text { include distance to nearest CBD, age, age2, size, floor-area ratio, green space, property management fees, parking fees, and } \\
\text { size, number of housing units and number of buildings of the complex. }{ }^{*} p<0.10,{ }^{* *} p<0.05,{ }^{* * *} p<0.01\end{array}$} \\
\hline
\end{tabular}


Table 4: CDR Policy and Income sorting near the Central Business District

\begin{tabular}{|c|c|c|c|c|c|c|c|}
\hline & (1) & $(2)$ & $(3)$ & (4) & $(5)$ & (6) & (7) \\
\hline Ln $($ Household Income $) \times C D R$ & $\begin{array}{l}-0.034 \\
(0.081)\end{array}$ & $\begin{array}{c}-0.052^{* * *} \\
(0.016)\end{array}$ & $\begin{array}{c}-0.051^{* * *} \\
(0.016)\end{array}$ & $\begin{array}{c}-0.048^{* * *} \\
(0.016)\end{array}$ & $\begin{array}{c}-0.038^{* *} \\
(0.016)\end{array}$ & $\begin{array}{l}-0.016 \\
(0.015)\end{array}$ & $\begin{array}{c}-0.012 \\
(0.015)\end{array}$ \\
\hline Ln(Household Income) & $\begin{array}{c}-0.756^{* * *} \\
(0.106)\end{array}$ & $\begin{array}{c}0.007 \\
(0.014)\end{array}$ & $\begin{array}{c}0.009 \\
(0.013)\end{array}$ & $\begin{array}{c}0.008 \\
(0.013)\end{array}$ & $\begin{array}{c}0.004 \\
(0.012)\end{array}$ & $\begin{array}{l}-0.009 \\
(0.012)\end{array}$ & $\begin{array}{c}-0.008 \\
(0.012)\end{array}$ \\
\hline Zip FE & & $\mathrm{Y}$ & $\mathrm{Y}$ & $\mathrm{Y}$ & $\mathrm{Y}$ & $\mathrm{Y}$ & $\mathrm{Y}$ \\
\hline Controls & & & $\mathrm{Y}$ & $\mathrm{Y}$ & $\mathrm{Y}$ & $\mathrm{Y}$ & $\mathrm{Y}$ \\
\hline Year-Month FE & & & & $\mathrm{Y}$ & & $\mathrm{Y}$ & \\
\hline Subway Line FE & & & & & & $\mathrm{Y}$ & $\mathrm{Y}$ \\
\hline DistrictxYear-Month Trend & & & & & $\mathrm{Y}$ & & $\mathrm{Y}$ \\
\hline Observations & 18135 & 18135 & 18135 & 18135 & 18135 & 18135 & 18135 \\
\hline Adjusted $R^{2}$ & 0.201 & 0.944 & 0.944 & 0.945 & 0.947 & 0.956 & 0.958 \\
\hline \multicolumn{8}{|c|}{$\begin{array}{l}\text { Note: Dependent variable is } \ln (\text { Distance to CBD }(\mathrm{km}) \text { ). Income is household monthly income ('000 yuan). CDR equals } \\
1 \text { after July } 202008 \text {. Standard errors clustered by zip code. Sample spans July 20, 2006-July 20, 2010. All specifications } \\
\text { include controls for year, month, and distance to subway. Controls include husband and wife age, employment rank, education, } \\
\text { employer type, and tenure. Subway Line FE is a fixed effect for the subway line associated with the housing unit's closest } \\
\text { subway station. }{ }^{*} p<0.10,{ }^{* *} p<0.05,{ }^{* *} p<0.01\end{array}$} \\
\hline
\end{tabular}

Table 5: CDR Policy and Income sorting near Subways

\begin{tabular}{|c|c|c|c|c|c|c|c|}
\hline & (1) & $(2)$ & $(3)$ & $(4)$ & $(5)$ & $(6)$ & $(7)$ \\
\hline Ln $($ Household Income $) \times$ CDR & $\begin{array}{l}-0.043 \\
(0.077)\end{array}$ & $\begin{array}{l}-0.014 \\
(0.050)\end{array}$ & $\begin{array}{l}-0.016 \\
(0.049)\end{array}$ & $\begin{array}{l}-0.025 \\
(0.048)\end{array}$ & $\begin{array}{l}-0.014 \\
(0.049)\end{array}$ & $\begin{array}{c}-0.083^{* * *} \\
(0.024)\end{array}$ & $\begin{array}{c}-0.079^{* * *} \\
(0.026)\end{array}$ \\
\hline Ln(Household Income) & $\begin{array}{c}-0.141^{*} \\
(0.073)\end{array}$ & $\begin{array}{c}0.003 \\
(0.037)\end{array}$ & $\begin{array}{c}0.006 \\
(0.035)\end{array}$ & $\begin{array}{c}0.012 \\
(0.035)\end{array}$ & $\begin{array}{c}0.007 \\
(0.034)\end{array}$ & $\begin{array}{l}0.050^{* *} \\
(0.022)\end{array}$ & $\begin{array}{l}0.048^{* *} \\
(0.022)\end{array}$ \\
\hline Zip FE & & $\mathrm{Y}$ & $\mathrm{Y}$ & $\mathrm{Y}$ & $\mathrm{Y}$ & $\mathrm{Y}$ & $\mathrm{Y}$ \\
\hline Controls & & & $\mathrm{Y}$ & $\mathrm{Y}$ & $\mathrm{Y}$ & $\mathrm{Y}$ & $\mathrm{Y}$ \\
\hline Year-Month FE & & & & $\mathrm{Y}$ & & $\mathrm{Y}$ & \\
\hline Subway Line FE & & & & & & $\mathrm{Y}$ & $\mathrm{Y}$ \\
\hline DistrictxYear-Month Trend & & & & & $\mathrm{Y}$ & & $\mathrm{Y}$ \\
\hline Observations & 18135 & 18135 & 18135 & 18135 & 18135 & 18135 & 18135 \\
\hline Adjusted $R^{2}$ & 0.637 & 0.912 & 0.913 & 0.913 & 0.915 & 0.923 & 0.924 \\
\hline \multicolumn{8}{|c|}{$\begin{array}{l}\text { Note: Dependent variable is } \ln (\text { Distance to Subway }(\mathrm{km}) \text { ). Income is household monthly income ('000 yuan). CDR equals } 1 \\
\text { after July } 20 \text { 2008. Standard errors clustered by zip code. Sample spans July } 20,2006-J u l y ~ 20,2010 \text {. All specifications include } \\
\text { controls for year, month, and distance to nearest CBD. Controls include husband and wife age, employment rank, education, } \\
\text { employer type, and tenure. Subway Line FE is a fixed effect for the subway line associated with the housing unit's closest } \\
\text { subway station. }{ }^{*} p<0.10,{ }^{* *} p<0.05,{ }^{* * *} p<0.01\end{array}$} \\
\hline
\end{tabular}




\section{Appendix A Figures and Tables}

Figure A1: Beijing Subway System Expansion

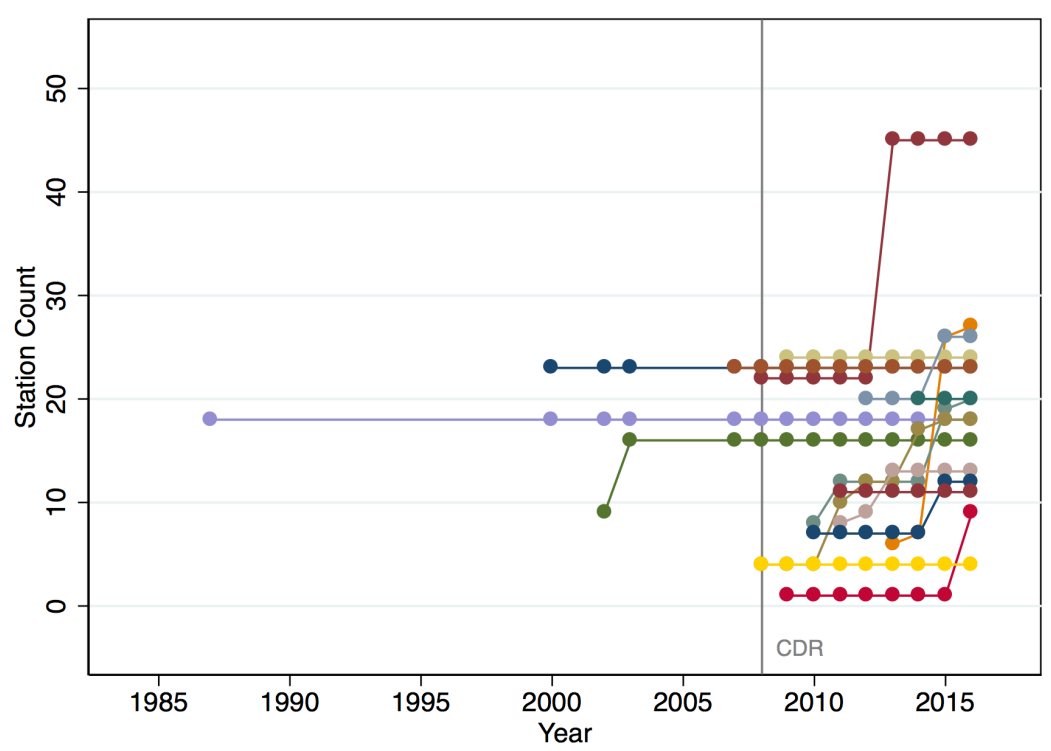

Note: Each color represents a subway line. Each dot denotes a date on which atleast one subway station was added across the Beijing system. Vertical shifts within a subway line show additions of stations connected to that subway line.

Figure A2: Beijing Housing Price Appreciation, 2005-2016

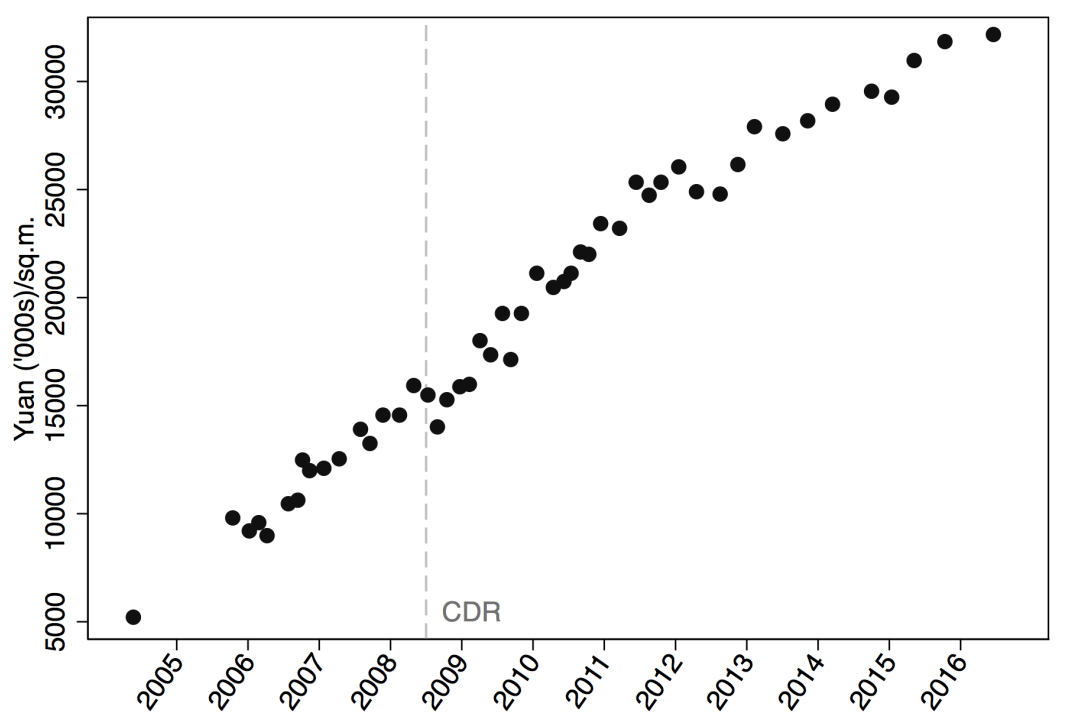

Note: Figure plots mean house price per square meter for 50 bins for transactions occuring from 2005 through 2016. Means residualized by jiedao fixed effects. Thus figure shows mean price appreciation within a jiedao over time. Source: Real estate transaction dataset. 
Figure A3: Google Search Trend Index for "Beijing Odd Even"

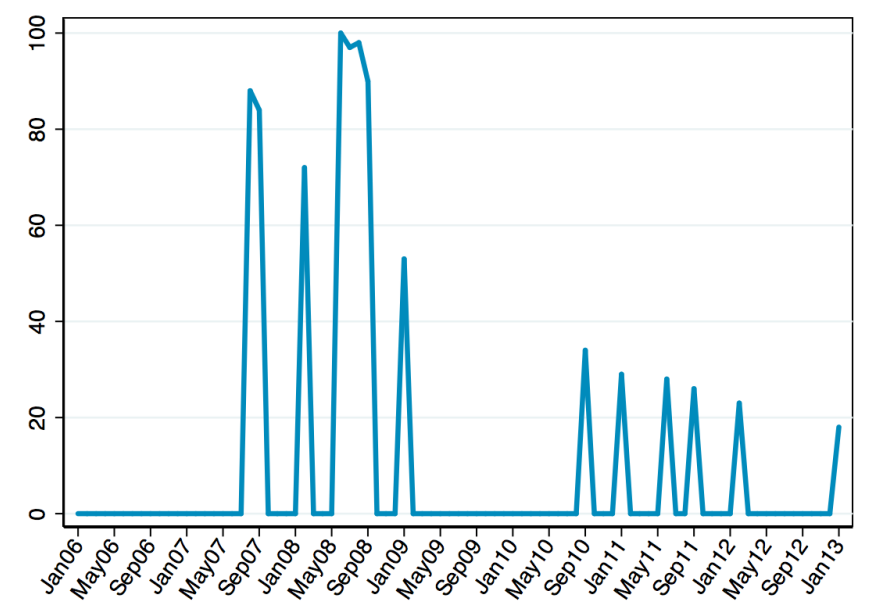

Note: Figure plots the relative popularity in Google searches worldwide for the term "Beijing Odd Even". Each data point is scaled on a range of 0 to 100 based on a topic's proprotion to all searches on all topics.

Figure A4: Comparison of Sample vs Population of Housing Transaction Volume

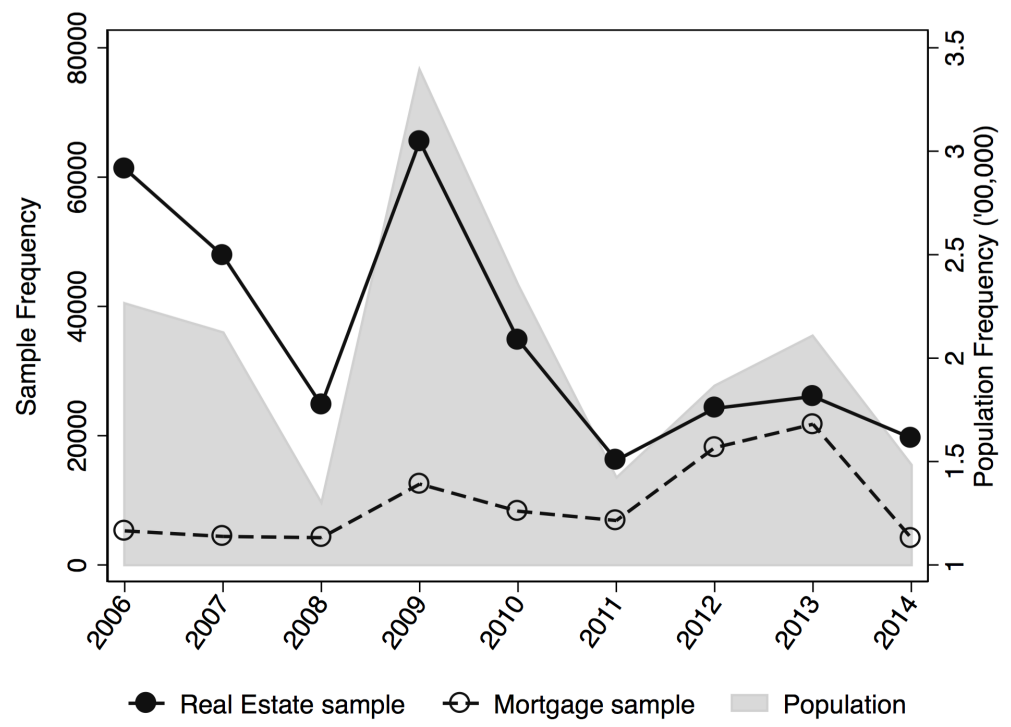

Note: Figure plots the population of housing transactions in Beijing from 2006 through 2014 in solid gray. Annual transaction volumes associated with the Real Estate data and Mortgage Applicaiton data shown in the solid and dashed black lines, respectively. 
Figure A5: Distribution of Jiedao Size

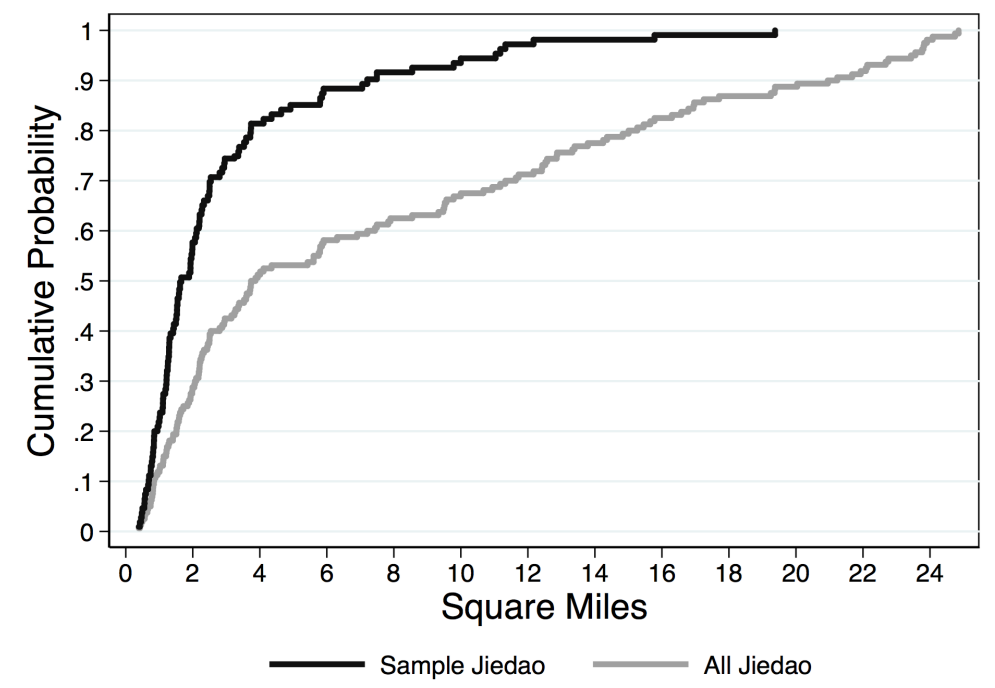

Note: Sample Jiedao include 188 neighborhoods. "All Jiedao" include population of neighborhoods, or 307 jiedao. 
Figure A6: Income-Distance Gradient with various definitions of CBD
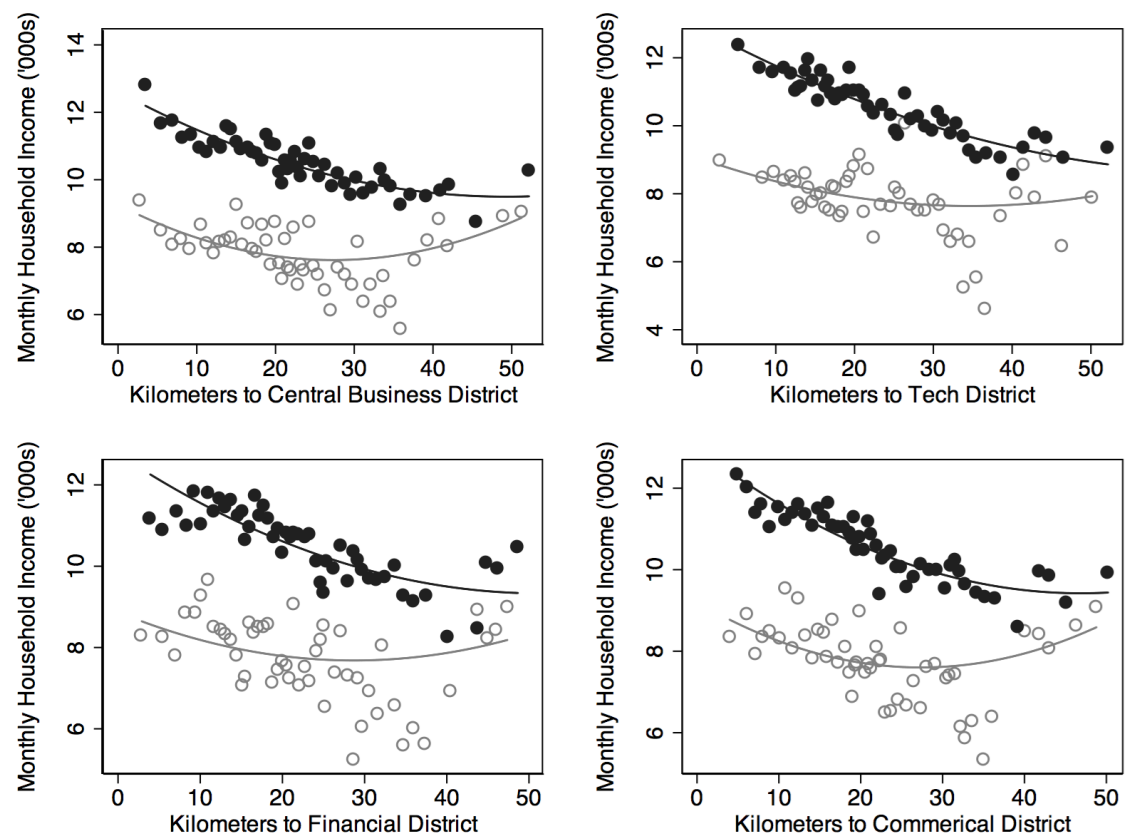

Note: Figure plots mean household income by binned distance to city center. Includes 50 bins each with 330 and 1400 obs per bin in pre and post periods, respectively. Means residualized by distance to the nearest subway.

Figure A7: Price-Distance Gradient with various definitions of CBD
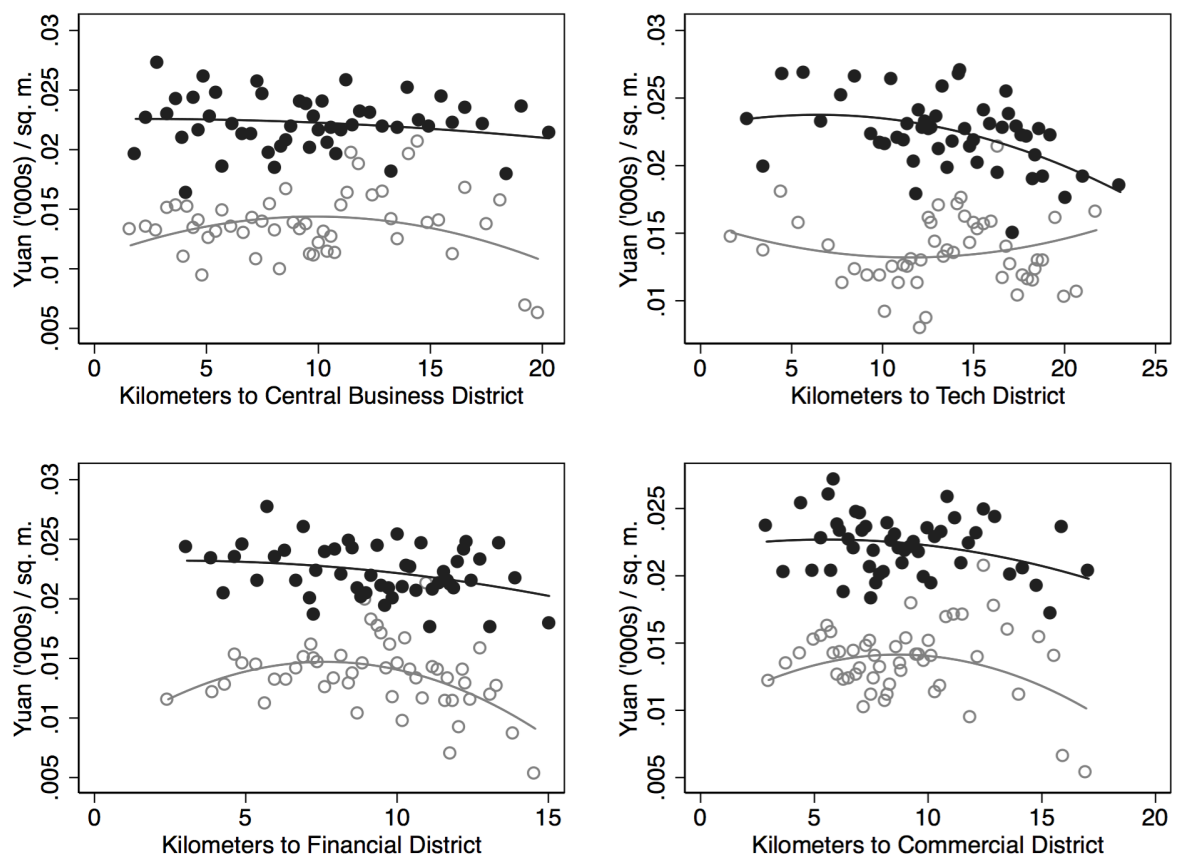

Note: Figure plots mean price per square meter by binned distance to city center. Includes 50 bins each with an average of 2500 and 5000 obs per bin in pre and post periods, respectively. Means residualized by distance to the nearest subway. 
Figure A8: Test for Gentrification Pre-Trends among Jiedao with New Subway Stations

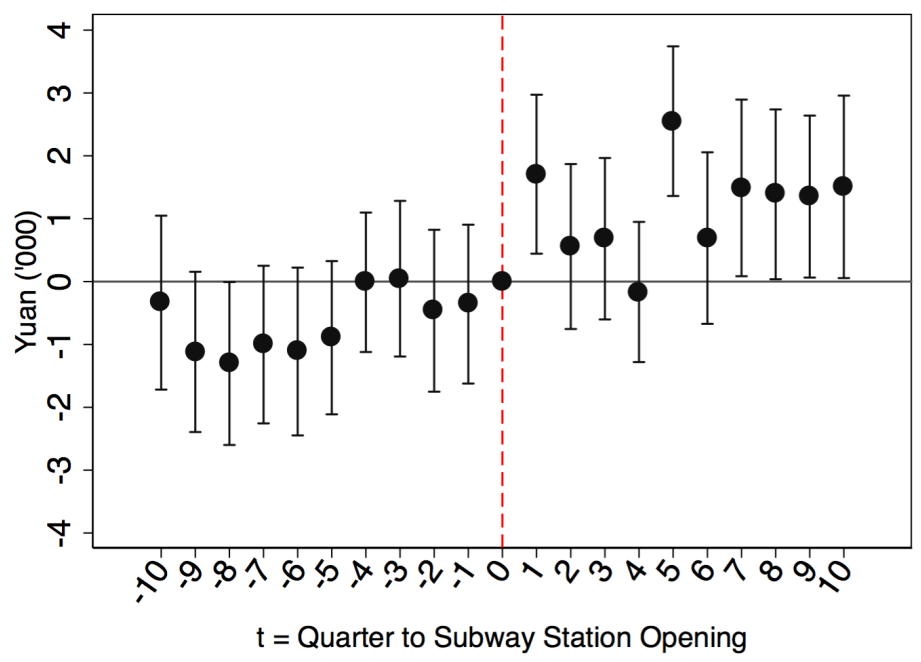

Note: Figure plots the difference in mean monthly household income in jiedao $j$ in quarter $q$ relative to quarter $q=0$ when a subway station opens in jiedao $j$. Point estimates residualized by quarter-of-year fixed effects. Includes a balanced panel of 24 jiedao over 21 quarters. Sample spans 2005 through 2014 and includes 56 station openings. Bands show $95 \%$ confidence intervals. Source: Mortgage loan application data.

Figure A9: Price Proximity Gradient, excluding areas near newly-built stations

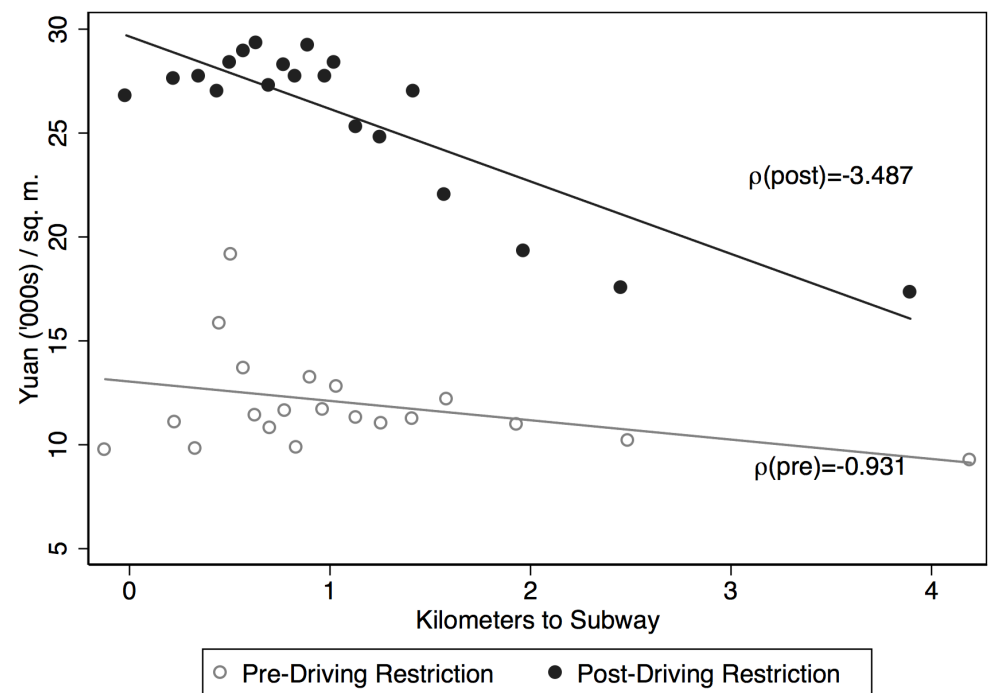

Note: Figure plots mean house price for each of 20 distance bins. Each dot represents 12,100 and 76,500 obs per bin in pre and post, respectively. Means are residualized by distance to the central business district. $\rho$ (pre) and $\rho$ (post) are regression coefficients. Includes years 2005-2016. Source: Real estate transaction dataset. 
Figure A10: Placebo Test of Road Rationing

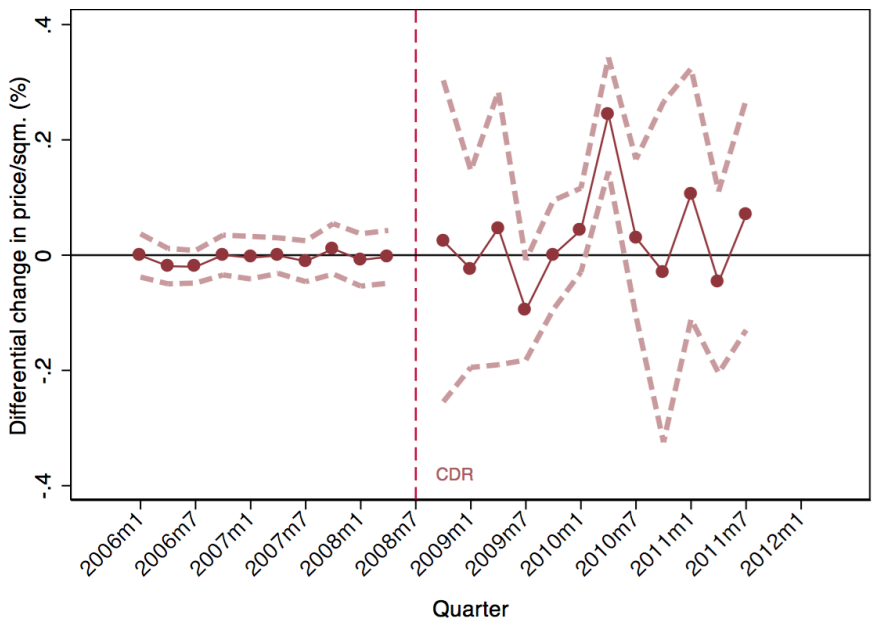

Note: Figure shows the partial effect of subway distance on housing price $\ln$ (total price/sqm in $¥ 2007$ ) at each quarter between Jan 2006 and Dec 2011. The omitted quarter is July-October 2008. Sample includes housing units located in building complexes that are over $3 \mathrm{~km}$ from the nearest subway station through the event period; but are under $3 \mathrm{~km}$ from a station after the event period ends (beginning in 2013). The sample includes 65,758 transactions. Controls include fixed effects for unit type (resale or newsale), jiedao, and year-quarter; as well as controls for distance to nearest CBD, age, age $^{2}$, size, floor-area ratio, green space, property management fee, parking fee, number of housing units and building units in complex, and unit size. Standard errors clustered at jiedao level. 
Figure A11: Placebo: Effects of CDR policy on Polluter-Price gradient

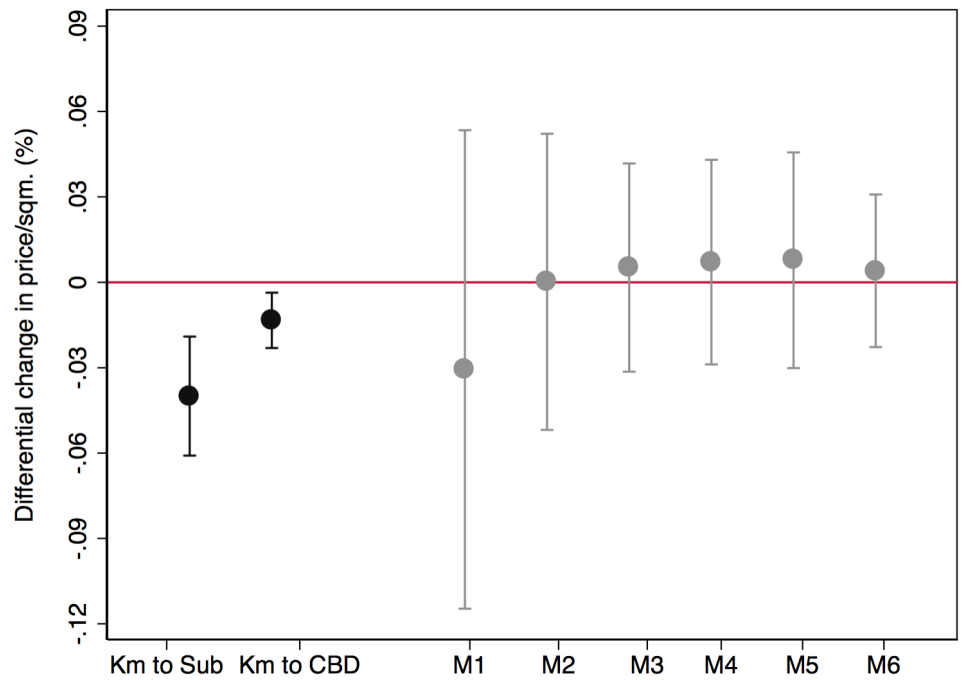

Note: Figure plots the effect of the CDR on the housing price premium for distance to one of three locations: the first and second estimates in black show the CDR effect for distance to a subway station and distance to a central business district, respectively. These estimates replicate column (4) in Tables 3 and 2, respectively. The gray dots show estimates of the CDR effect for distance to a major pollution site under various specifications. All models include year and month fixed effects. Sample includes 82,002 transactions, spanning July 2007 through July 2009. Model "M2" adds jiedao fixed effects. "M3" adds controls for: unit type (resale or newsale), distance to nearest CBD (or subway in the CBD regression), age, age $^{2}$, size, floor-area ratio, green space, property management fee, parking fee, number of housing units and building units in complex, and unit size. "M4" adds year-by-month fixed effects. "M5" includes all controls as well as district by year-month linear time trends. Finally, "M6" includes all controls as well as complex fixed effects. Standard errors clustered at jiedao level.

Figure A12: Placebo: CDR policy and income sorting near pollution centers

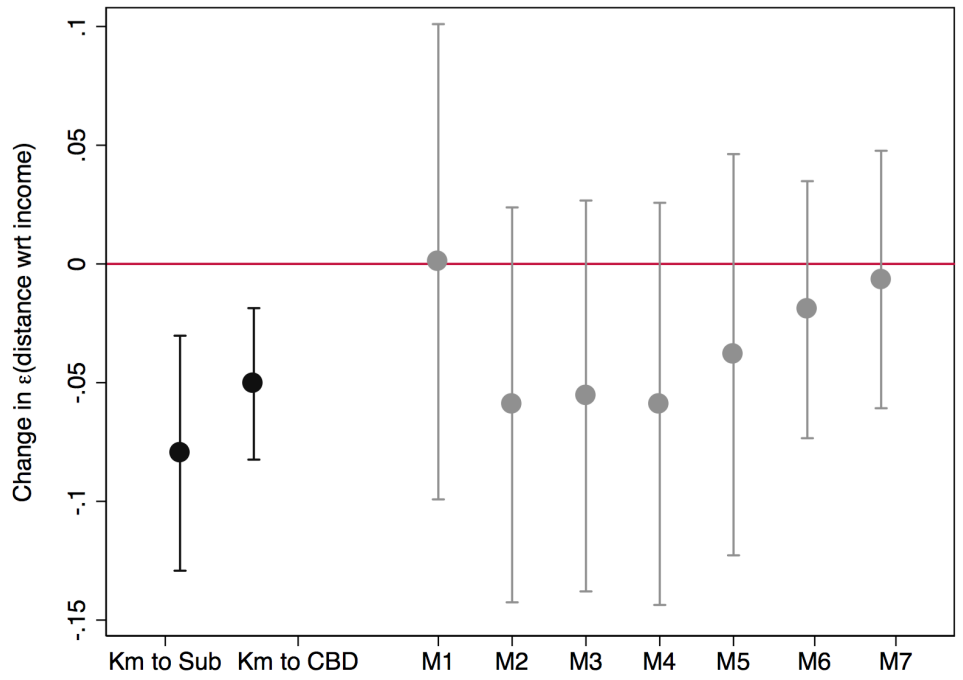

Note: Figure plots the effect of the CDR on the elasticity of distance with respect to income. Distance is defined as kilometers to one of three locations: the first and second estimates in black show the CDR effect for distance to a subway station and distance to a central business district, respectively. These estimates replicate column (6) in Table 5 and column (4) in 4. The gray dots show estimates of the CDR effect for distance to a major pollution site under various specifications. All models include year and month fixed effects. Sample includes 18,414 transactions, spanning July 2006 through July 2010. "M2" adds neighborhood (zip code) fixed effects. "M3" adds controls for husband and wife age, employment rank, education, employer type, tenure, and distance to nearest CBD (or subway in the second estimate.) "M4" adds year-by-month fixed effects. "M5" includes all controls as well as district by year-month linear time trends. "M6" includes all controls, year-by-month fixed effects, and subway line fied effects. "M7" includes all controls, district by year-month linear time trends, and subway-line fixed effects. Standard errors clustered by neighborhood. 
Figure A13: Urban Land Use and Equilibrium Sorting with Income Heterogeneity

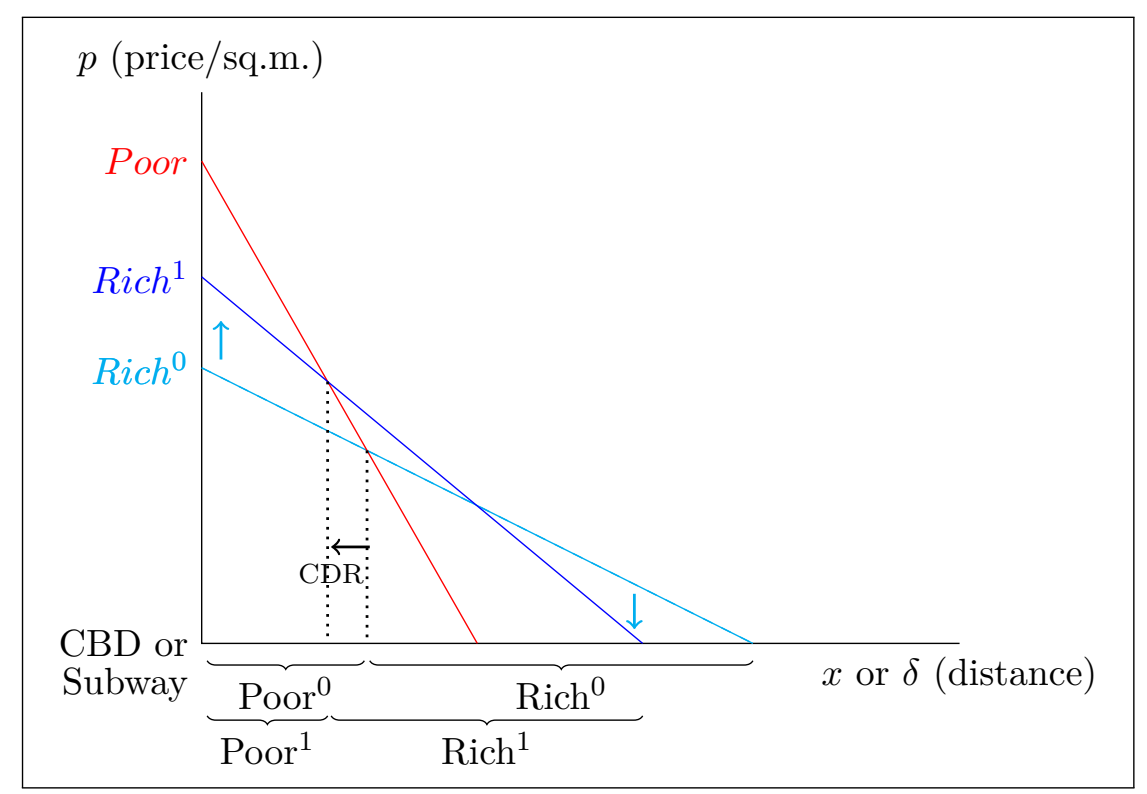

Note: $\mathrm{y}$-axis is price per square meter and the $\mathrm{x}$-axis is distance from the CBD or a subway station, respectively. Location in the city is defined by $x$ conditional on $\delta$ and vice verca. Each income group has a distinct bid-rent gradient. Let $\epsilon_{h, y}>\epsilon_{t, y}$ (i.e., income elasticity of housing $>$ income elasticity of time costs). Consequently, the poor have a steeper gradient than the rich, ex ante. The car driving restriction (CDR) increases the cost of commuting for the rich, thus they increase their demand for locations proximate to both the CBD and subway stations, depicted as a tilt from Rich ${ }^{0}$ to $R i c h^{1}$. The CDR identifies $\frac{\partial p^{2}}{\partial x \partial(C D R)}$ and $\frac{\partial p^{2}}{\partial \delta \partial(C D R)}$. The CDR causes the price per square meter to increase for all units from the intersection of Poor and Rich ${ }^{1}$ to the intersection of Poor and Rich ${ }^{0}$. This also causes the rich to outbid the poor for units along the x-axis within the horizontal dotted lines. 
Table A1: Effects of CDR policy on City Center-Price gradient- Varying Definition of CBD

\begin{tabular}{lcccccccc}
\hline & \multicolumn{1}{c}{$[\mathrm{CBD}]=$} \\
\cline { 2 - 8 } & $\begin{array}{c}\text { Geographic } \\
\text { Center }\end{array}$ & $\begin{array}{c}\text { Technology } \\
\text { District }\end{array}$ & $\begin{array}{c}\text { Software } \\
\text { District }\end{array}$ & $\begin{array}{c}\text { Financial } \\
\text { District }\end{array}$ & $\begin{array}{c}\text { Beijing } \\
\text { "CBD" }\end{array}$ & $\begin{array}{c}\text { Embassy } \\
\text { District }\end{array}$ & $\begin{array}{c}\text { Business } \\
\text { Park }\end{array}$ & $\begin{array}{c}\text { Shopping } \\
\text { District }\end{array}$ \\
\hline Km to [CBD] x CDR & -0.007 & $-0.008^{* * *}$ & $-0.007^{* * *}$ & $-0.009^{*}$ & $-0.006^{* *}$ & -0.005 & $-0.006^{* *}$ & $-0.010^{* *}$ \\
& $(0.005)$ & $(0.003)$ & $(0.002)$ & $(0.005)$ & $(0.003)$ & $(0.004)$ & $(0.002)$ & $(0.005)$ \\
Km to [CBD] & 0.023 & 0.020 & 0.015 & $0.036^{* *}$ & 0.006 & 0.005 & 0.007 & 0.021 \\
& $(0.017)$ & $(0.012)$ & $(0.012)$ & $(0.017)$ & $(0.013)$ & $(0.014)$ & $(0.013)$ & $(0.017)$ \\
\hline Year \& Month FE & $\mathrm{Y}$ & $\mathrm{Y}$ & $\mathrm{Y}$ & $\mathrm{Y}$ & $\mathrm{Y}$ & $\mathrm{Y}$ & $\mathrm{Y}$ & $\mathrm{Y}$ \\
Jiedao FE & $\mathrm{Y}$ & $\mathrm{Y}$ & $\mathrm{Y}$ & $\mathrm{Y}$ & $\mathrm{Y}$ & $\mathrm{Y}$ & $\mathrm{Y}$ & $\mathrm{Y}$ \\
Controls & $\mathrm{Y}$ & $\mathrm{Y}$ & $\mathrm{Y}$ & $\mathrm{Y}$ & $\mathrm{Y}$ & $\mathrm{Y}$ & $\mathrm{Y}$ & $\mathrm{Y}$ \\
\hline Avg Price Premium $/ \mathrm{Km}$ & $\$ 633.04$ & $\$ 695.82$ & $\$ 630.24$ & $\$ 727.10$ & $\$ 537.56$ & $\$ 404.06$ & $\$ 484.61$ & $\$ 857.16$ \\
\hline Observations & 82002 & 82002 & 82002 & 82002 & 82002 & 82002 & 82002 & 82002 \\
Adjusted $R^{2}$ & 0.609 & 0.609 & 0.609 & 0.610 & 0.608 & 0.607 & 0.608 & 0.609 \\
\hline
\end{tabular}

Note: Dependent variable is $\ln$ (total price per square meter in 2007 real Yuan). Standard errors clustered at jiedao level. Sample spans 12 mos. before and after CDR. Average price premium is evaluated at a unit size of $122 \mathrm{sqm}$, the size at the mean distance to the nearest business district ( 5 and $7 \mathrm{~km}$ ), and at a conversion rate of 6.95 yuan per USD. Controls include fixed effects for unit type (newsale vs resale), top floor, floor level, facing direction, no. bedrooms, decoration level, ownership type, and total number of floors in building. Continuous controls include distance to nearest subway station, age, age2, size, floor-area ratio, green space, property management fees, parking fees, and size, number of housing units and number of buildings of the complex. $p<0.10,{ }^{* *} p<0.05,{ }^{* * *} p<0.01$

Table A2: Comparison of CDR Effects with Xu et al. (2015)

\begin{tabular}{|c|c|c|c|c|c|c|c|c|}
\hline & \multicolumn{4}{|c|}{ CDR is October 11} & \multicolumn{4}{|c|}{ CDR is July 20} \\
\hline & (1) & $(2)$ & $(3)$ & $(4)$ & $(5)$ & (6) & (7) & $(8)$ \\
\hline Ln(Distance to Subway) & $\begin{array}{c}-0.081^{* *} \\
(0.038)\end{array}$ & $\begin{array}{c}0.071 \\
(0.049)\end{array}$ & $\begin{array}{l}-0.022 \\
(0.023)\end{array}$ & $\begin{array}{c}-0.085^{* *} \\
(0.039)\end{array}$ & $\begin{array}{c}-0.096^{* *} \\
(0.038)\end{array}$ & $\begin{array}{c}0.010 \\
(0.057)\end{array}$ & $\begin{array}{c}-0.057^{* * *} \\
(0.019)\end{array}$ & $\begin{array}{c}-0.124^{* *} \\
(0.050)\end{array}$ \\
\hline Ln(Distance to Subway) x CDR & $\begin{array}{c}-0.069 \\
(0.049) \\
\end{array}$ & $\begin{array}{c}-0.107^{* * *} \\
(0.030)\end{array}$ & $\begin{array}{c}-0.068^{* * *} \\
(0.023)\end{array}$ & & $\begin{array}{l}-0.085 \\
(0.055) \\
\end{array}$ & $\begin{array}{c}-0.077^{* *} \\
(0.031) \\
\end{array}$ & $\begin{array}{c}-0.049^{* * *} \\
(0.013)\end{array}$ & \\
\hline Location Controls & $\mathrm{Y}$ & & & $\mathrm{Y}$ & $\mathrm{Y}$ & & & $\mathrm{Y}$ \\
\hline Full Controls & & & $\mathrm{Y}$ & & & & $\mathrm{Y}$ & \\
\hline Jiedao FE & & $\mathrm{Y}$ & $\mathrm{Y}$ & & & $\mathrm{Y}$ & $\mathrm{Y}$ & \\
\hline 6 mos. pre CDR & & & & $\mathrm{Y}$ & & & & $\mathrm{Y}$ \\
\hline Observations & 18989 & 18981 & 18981 & 5917 & 14061 & 14051 & 14051 & 6016 \\
\hline Adjusted $R^{2}$ & 0.223 & 0.630 & 0.720 & 0.166 & 0.189 & 0.654 & 0.731 & 0.101 \\
\hline
\end{tabular}


Table A3: CDR Policy and Income sorting near the Central Business District- Varying Definition of CBD

\begin{tabular}{|c|c|c|c|c|c|c|c|c|}
\hline & $\begin{array}{c}\text { Geographic } \\
\text { Center }\end{array}$ & $\begin{array}{c}\text { Technology } \\
\text { District }\end{array}$ & $\begin{array}{c}\text { Software } \\
\text { District }\end{array}$ & $\begin{array}{c}\text { Financial } \\
\text { District }\end{array}$ & $\begin{array}{l}\text { Beijing } \\
\text { "CBD" }\end{array}$ & $\begin{array}{c}\text { Embassy } \\
\text { District }\end{array}$ & $\begin{array}{c}\text { Business } \\
\text { Park }\end{array}$ & $\begin{array}{c}\text { Shopping } \\
\text { District }\end{array}$ \\
\hline $\operatorname{Ln}($ Household Income $) \times C D R$ & $\begin{array}{c}-0.010^{* *} \\
(0.004)\end{array}$ & $\begin{array}{c}0.002 \\
(0.006)\end{array}$ & $\begin{array}{c}-0.009^{* *} \\
(0.005)\end{array}$ & $\begin{array}{c}0.002 \\
(0.004)\end{array}$ & $\begin{array}{c}-0.020^{* * *} \\
(0.005)\end{array}$ & $\begin{array}{c}-0.015^{\text {*** }} \\
(0.005)\end{array}$ & $\begin{array}{c}-0.021^{* * *} \\
(0.005)\end{array}$ & $\begin{array}{c}-0.011^{* * *} \\
(0.004)\end{array}$ \\
\hline Ln(Household Income) & $\begin{array}{l}-0.001 \\
(0.004)\end{array}$ & $\begin{array}{c}-0.011^{* *} \\
(0.005)\end{array}$ & $\begin{array}{l}-0.003 \\
(0.004)\end{array}$ & $\begin{array}{c}-0.009^{* *} \\
(0.004)\end{array}$ & $\begin{array}{l}0.009^{* *} \\
(0.004)\end{array}$ & $\begin{array}{c}0.003 \\
(0.004)\end{array}$ & $\begin{array}{l}0.009^{*} \\
(0.005)\end{array}$ & $\begin{array}{c}0.000 \\
(0.004)\end{array}$ \\
\hline Year \& Month FE & $\mathrm{Y}$ & $\mathrm{Y}$ & $\mathrm{Y}$ & $\mathrm{Y}$ & $\mathrm{Y}$ & $\mathrm{Y}$ & $\mathrm{Y}$ & $\mathrm{Y}$ \\
\hline Zip FE & $\mathrm{Y}$ & $\mathrm{Y}$ & $\mathrm{Y}$ & $\mathrm{Y}$ & $\mathrm{Y}$ & $\mathrm{Y}$ & $\mathrm{Y}$ & $\mathrm{Y}$ \\
\hline Controls & $\mathrm{Y}$ & $\mathrm{Y}$ & $\mathrm{Y}$ & $\mathrm{Y}$ & $\mathrm{Y}$ & $\mathrm{Y}$ & $\mathrm{Y}$ & $\mathrm{Y}$ \\
\hline Subway Line FE & $\mathrm{Y}$ & Y & Y & $\mathrm{Y}$ & $\mathrm{Y}$ & Y & Y & $\mathrm{Y}$ \\
\hline Observations & 18135 & 18135 & 18135 & 18135 & 18135 & 18135 & 18135 & 18135 \\
\hline Adjusted $R^{2}$ & 0.979 & 0.957 & 0.959 & 0.980 & 0.967 & 0.972 & 0.963 & 0.978 \\
\hline
\end{tabular}

Note: Dependent variable is $\ln$ (Distance to CBD (km)). Income is household monthly income ('000 yuan). CDR equals 1 after July 202008. Standard errors clustered by zip code. Sample spans July 20, 2006-July 20, 2010. Controls include distance to nearest subway, husband and wife age, employment rank, education, employer type, and tenure. Subway Line FE is a fixed effect for the subway line associated with the housing unit's closest subway station. ${ }^{*} p<0.10,{ }^{* *} p<0.05,{ }^{* * *} p<0.01$

Table A4: Effects of CDR policy on Subway-Price gradient, excluding houses near newly-built stations

\begin{tabular}{|c|c|c|c|c|c|c|}
\hline & (1) & $(2)$ & $(3)$ & (4) & $(5)$ & $(6)$ \\
\hline Km to Subway x CDR & $\begin{array}{l}-0.020 \\
(0.019)\end{array}$ & $\begin{array}{c}-0.022^{* * *} \\
(0.006)\end{array}$ & $\begin{array}{c}-0.024^{* * *} \\
(0.005)\end{array}$ & $\begin{array}{c}-0.012^{* * *} \\
(0.004)\end{array}$ & $\begin{array}{c}-0.027^{* * *} \\
(0.005)\end{array}$ & $\begin{array}{c}-0.024^{* * *} \\
(0.004)\end{array}$ \\
\hline Km to Subway & $\begin{array}{c}-0.109^{* * *} \\
(0.015)\end{array}$ & $\begin{array}{c}-0.053^{* * *} \\
(0.009)\end{array}$ & $\begin{array}{c}-0.043^{* * *} \\
(0.015)\end{array}$ & $\begin{array}{c}-0.049^{* * *} \\
(0.015)\end{array}$ & $\begin{array}{c}-0.040^{* *} \\
(0.016)\end{array}$ & \\
\hline Controls & & $\mathrm{Y}$ & $\mathrm{Y}$ & $\mathrm{Y}$ & $\mathrm{Y}$ & $\mathrm{Y}$ \\
\hline Jiedao FE & & & $\mathrm{Y}$ & $\mathrm{Y}$ & $\mathrm{Y}$ & $\mathrm{Y}$ \\
\hline Year-Month FE & & & & $\mathrm{Y}$ & & \\
\hline DistrictxYear-Month Trend & & & & & $\mathrm{Y}$ & \\
\hline Building Complex FE & & & & & & $\mathrm{Y}$ \\
\hline Avg Price Premium / Km & $\$ 1694.84$ & $\$ 1902.35$ & $\$ 2062.51$ & $\$ 1005.90$ & $\$ 2324.19$ & $\$ 2040.08$ \\
\hline Observations & 12474 & 12474 & 12474 & 12474 & 12474 & 12147 \\
\hline Adjusted $R^{2}$ & 0.191 & 0.635 & 0.731 & 0.741 & 0.732 & 0.801 \\
\hline \multicolumn{7}{|c|}{$\begin{array}{l}\text { Note: Dependent variable is } \ln \text { (total price per square meter in } 2007 \text { real Yuan). Sample includes housing units in } \\
\text { building complexes that do not change in their proximity to subway stations from } 2005 \text { through } 2016 \text {. Standard errors } \\
\text { clustered at jiedao level. Sample spans } 12 \text { mos. before and after CDR. All specifications include year and month fixed } \\
\text { effects. Average price premium is evaluated at a unit size of } 115 \mathrm{sqm} \text {, the size at the mean distance (between } 2 \text { and } \\
4 \mathrm{~km} \text { ) to the nearest subway station, and at a conversion rate of } 6.95 \text { yuan per USD. Controls include fixed effects } \\
\text { for unit type (newsale vs resale), top floor, floor level, facing direction, no. bedrooms, decoration level, ownership } \\
\text { type, and total number of floors in building. Continuous controls include distance to nearest CBD, age, age } 2 \text {, size, } \\
\text { floor-area ratio, green space, property management fees, parking fees, and size, number of housing units and number } \\
\text { of buildings of the complex. }{ }^{*} p<0.10,{ }^{* *} p<0.05,{ }^{* * *} p<0.01\end{array}$} \\
\hline
\end{tabular}




\section{Appendix B Derivation of the Bid Rent Gradient}

Residents face the following maximization problem:

$$
\begin{gathered}
\max _{z, h} U(z, h) \text { s.t. } \\
z+p h+t(n, x, \delta) w=y
\end{gathered}
$$

where the transit cost $t(n, x)$ differs depending on how likely an individual is to utilize the subway versus driving a car. The variable $n$ ranges between 0 and 1 and measures the likelihood of commuting via subway. For the rich, $n$ approximates zero because they are more likely to rely on cars to commute, except on road rationing days. Thus, we can define transit costs as in Eq. 1 as follows:

$$
t(n, x, \delta)=n\left[\frac{\delta}{\omega}+\frac{x}{\sigma}\right]+(1-n) \frac{x}{\nu}
$$

The first term in brackets encompasses transit time for commuting via subway: walking time to the station, which depends on the distance of the walk $\delta$ divided by walking speed $(\omega)$ and time on the subway to the CBD, which is distance divided by subway speed $(x / \sigma)$. The second term encompasses transit time via car where car speed is $\nu$. We assume car speed is greater than subway speed, which is greater than walking speed $(\nu>\sigma>\omega)$.

In equilibrium, all residents $i$ have achieved their highest utility subject to their time and budget constraints, and all residents have equal utility levels, $\max _{z, h} u_{i}=\bar{u} \forall i$. This is achieved by the tradeoffs throughout the city of housing prices and commuting costs. Substituting the first budget constraint into Eq. 10, the equal utility condition is:

$$
\max _{h} u_{i}(y-p h-t(n, x, \delta) w, h)=\bar{u} \forall i
$$

Equations 10 and 12 are the two conditions required for equilibrium.

We derive the first order conditions of Eq. 10 by setting up a Lagrangian equation:

$$
\mathcal{L}=u(z, h)+\lambda[y-p h-t(n, x, \delta) w-z]
$$

The first derivative of $\mathcal{L}$ with respect to choice variables $h$ and $z$ are as follows:

$$
\begin{aligned}
& \frac{\partial \mathcal{L}}{\partial z}=\frac{\partial u}{\partial z}-\lambda=0 \rightarrow \frac{\partial u}{\partial z}=\lambda \\
& \frac{\partial \mathcal{L}}{\partial h}=\frac{\partial u}{\partial h}-\lambda p=0 \rightarrow \frac{\partial u}{\partial h}=\lambda p
\end{aligned}
$$

Dividing the first condition by the second: 


$$
\frac{\partial u / \partial h}{\partial u / \partial z}=p \text { or, equivalently } \frac{v_{2}}{v_{1}}=p
$$

where $v_{1}$ denotes the partial derivative of the first argument in Eq. 10 and $v_{2}$ denotes that of the second argument.

Next, we totally differentiate Eq. 12 with respect to $x$ to solve the system of equilibrium conditions:

$$
v_{1} \frac{\partial y}{\partial x}-v_{1}\left[\frac{\partial p}{\partial x} h+\frac{\partial h}{\partial x} p\right]-v_{1}\left[\frac{\partial t}{\partial x} w+\frac{\partial w}{\partial x} t\right]+v_{2} \frac{\partial h}{\partial x}=0
$$

Since $y$ and $w$ do not vary with $x$, we are left with:

$$
v_{1}\left[\frac{\partial p}{\partial x} h+\frac{\partial h}{\partial x} p\right]+v_{1}\left[\frac{\partial t}{\partial x}\right] w=v_{2} \frac{\partial h}{\partial x}
$$

From the first order conditions, we can substitute $\frac{v_{2}}{v_{1}}=p$, or $v_{2}=v_{1} p$ into the above equation:

$$
-\frac{\partial t}{\partial x} w=\frac{\partial p}{\partial x} h
$$

From Eq. 11, the left-hand side is equivalently:

$$
-\left[\frac{n}{\sigma}+\frac{1-n}{\nu}\right] w=\frac{\partial p}{\partial x} h
$$

Solving for the change in price with respect to distance from the CBD, we obtain the bid rent function that demonstrates how housing prices fall with distance from the CBD at a rate proportional to the increased commuting costs required to reach the CBD from a distance $x$ :

$$
\frac{\partial p}{\partial x}=-\left[\frac{n}{\sigma}+\frac{1-n}{\nu}\right] \frac{w}{h}
$$

which is Eq. 2 in the main text.

We similarly derive the bid rent gradient for subway station proximity by totally differentiating Eq. 12 with respect to $\delta$. Eq. 13 is instead:

$$
-\frac{\partial t}{\partial \delta} w=\frac{\partial p}{\partial \delta} h
$$

From Eq. 11, the left-hand side is equivalently:

$$
-\frac{n}{\omega} w=\frac{\partial p}{\partial \delta} h \rightarrow \frac{\partial p}{\partial \delta}=-\frac{n}{\omega} \frac{w}{h}
$$

which is Eq. 3 in the main text. Appendix Figure A13 graphically depicts $\frac{\partial p}{\partial x}$ and $\frac{\partial p}{\partial \delta}$. The same framework is applicable whether the origin is the central business district with distance $x$ or a subway 
station with distance $\delta$. Rich and Poor having different slopes, dictated by their respective cost of commuting and time value, as discussed in the text. This paper's empirical approach estimates the magnitude of the change in slope following the CDR. In the simplified case of the Figure, we empirically estimate the slope change from Rich $^{0}$ to Rich $^{1}$. 